\title{
2016 update to The American Association for Thoracic Surgery (AATS) consensus guidelines: Ischemic mitral valve regurgitation
}

\author{
AATS Ischemic \\ Mitral \\ Regurgitation \\ Consensus \\ Guidelines Writing \\ Committee: \\ Irving L. Kron, MD, ${ }^{\mathrm{a}}$ Damien J. LaPar, MD, MSc, ${ }^{\mathrm{a}}$ \\ Michael A. Acker, MD, ${ }^{\mathrm{b}}$ David H. Adams, MD, \\ Gorav Ailawadi, MD, ${ }^{a}$ Steven F. Bolling, MD, ${ }^{d}$ \\ Judy W. Hung, MD, ${ }^{e}$ D. Scott Lim, MD, ${ }^{f}$ \\ Michael J. Mack, MD, ${ }^{\mathrm{g}}$ Patrick T. O'Gara, MD, \\ Michael K. Parides, PhD, ${ }^{\mathrm{i}}$ and John D. Puskas, $\mathrm{MD}^{\mathrm{c}}$
}

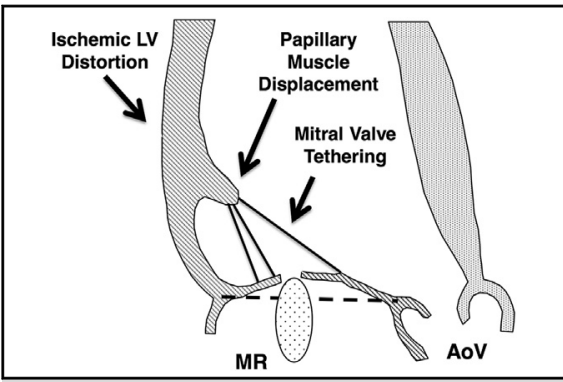

Illustrated mechanism of ischemic mitral regurgitation. Apically displaced leaflet coaptation with restricted leaflet closure results in mitral regurgitation.

Central Message

This contribution provides an update to the 2015 AATS evidence-based guidelines for the management of ischemic mitral regurgitation.

See Editorial Commentary page 1080.

\section{TABLE OF CONTENTS}

Rationale and Objectives . . . . . . . . . . . . . . . . . . . . . . . . . . . . . . . . Methods of Review . . . . . . . . . . . . . . . . . . .e98 SECTION I: Introduction-Limitation to IMR Guidelines . .e98 SECTION II: Definitions and Mechanisms of IMR . . . . . . e99

Definition of IMR . . . . . . . . . . . . . . . . . . . . . . e99

SECTION III: Imaging of IMR . . . . . . . . . . . . . . . e99

Imaging Features of IMR . . . . . . . . . . . . . e e99

Grading of MR: How to Do It . . . . . . . . . . . e101

General considerations . . . . . . . . . . . . . e101

Doppler Methods . . . . . . . . . . . . . . . . .e101

Distal jet area method . . . . . . . . . . . e101

Vena contracta width . . . . . . . . . . . . e102

PISA method ................... . e102

Factors influencing the PISA method........ . e103

Different reference values for EROA based

on etiology of MR . . . . . . . . . . e104

From the a Division of Thoracic and Cardiovascular Surgery, Department of Surgery, and ${ }^{\mathrm{f}}$ Division of Pediatric Cardiology, Departments of Pediatrics and Medicine, University of Virginia, Charlottesville, Va; ${ }^{b}$ Division of Cardiovascular Surgery, Department of Surgery, University of Pennsylvania School of Medicine University of Pennsylvania, Philadelphia, Pa; ' ${ }^{\circ}$ Department of Cardiac Surgery, Mount Sinai Medical Center; ${ }^{\mathrm{d} D e p a r t m e n t}$ of Cardiac Surgery, University of Michigan, Ann Arbor, Mich; ${ }^{\mathrm{e}}$ Division of Cardiology, Department of Medicine, Massachusetts General Hospital; ${ }^{g}$ Department of Cardiovascular Surgery, Heart Hospital Baylor Plano, Baylor Health Care System, Plano, Tex; ${ }^{\text {h}}$ Cardiovascular Division, Department of Medicine, Brigham and Women's Hospital, Boston, Mass; and 'The International Center for Health Outcomes and Innovation Research (InCHOIR),
Supportive criteria . . . . . . . . . . . . . . . . . e104

Transesophageal echocardiography (TEE)

assessment of MR severity . . . . . . . . . e105 Putting It All Together: Importance of the Integrative Method. e105 SECTION IV: Indications for Surgery in Patients With IMR . . e105

Treatment of IMR . . . . . . . . . . . . . . . . . . e105

Medical therapy. . . . . . . . . . . . . . e105

Resynchronization therapy for secondary MR . . . e 105

Coronary revascularization . . . . . . . . . e106

Indications for surgery in IMR . . . . . . . . . e106

SECTION V: Surgical Guidelines for the Treatment

of IMR. . . . . . . . . . . . . . . . . . e108

Repair versus Replacement for Severe IMR . . . . . . . . .e108

Patients With Severe IMR . . . . . . . . . . . . . e108

Surgical Decision Making in Patients With Moderate

IMR Undergoing CABG. . . . . . . . . . . . . . . . . . e108

Technical Aspects of MV Repair for IMR . . . . . . . . .e109

Department of Population Health Science and Policy, Icahn School of Medicine at Mount Sinai, New York, NY.

Received for publication Jan 31, 2017; accepted for publication Jan 31, 2017.

Address for reprints: Irving L. Kron, MD, Division of Thoracic and Cardiovascular

Surgery, Department of Surgery, University of Virginia School of Medicine, PO

Box 800679, Charlottesville, VA 22908 (E-mail: ilk@virginia.edu).

J Thorac Cardiovasc Surg 2017;153:e97-114

0022-5223/\$36.00

Copyright (C) 2017 by The American Association for Thoracic Surgery

http://dx.doi.org/10.1016/j.jtcvs.2017.01.031 


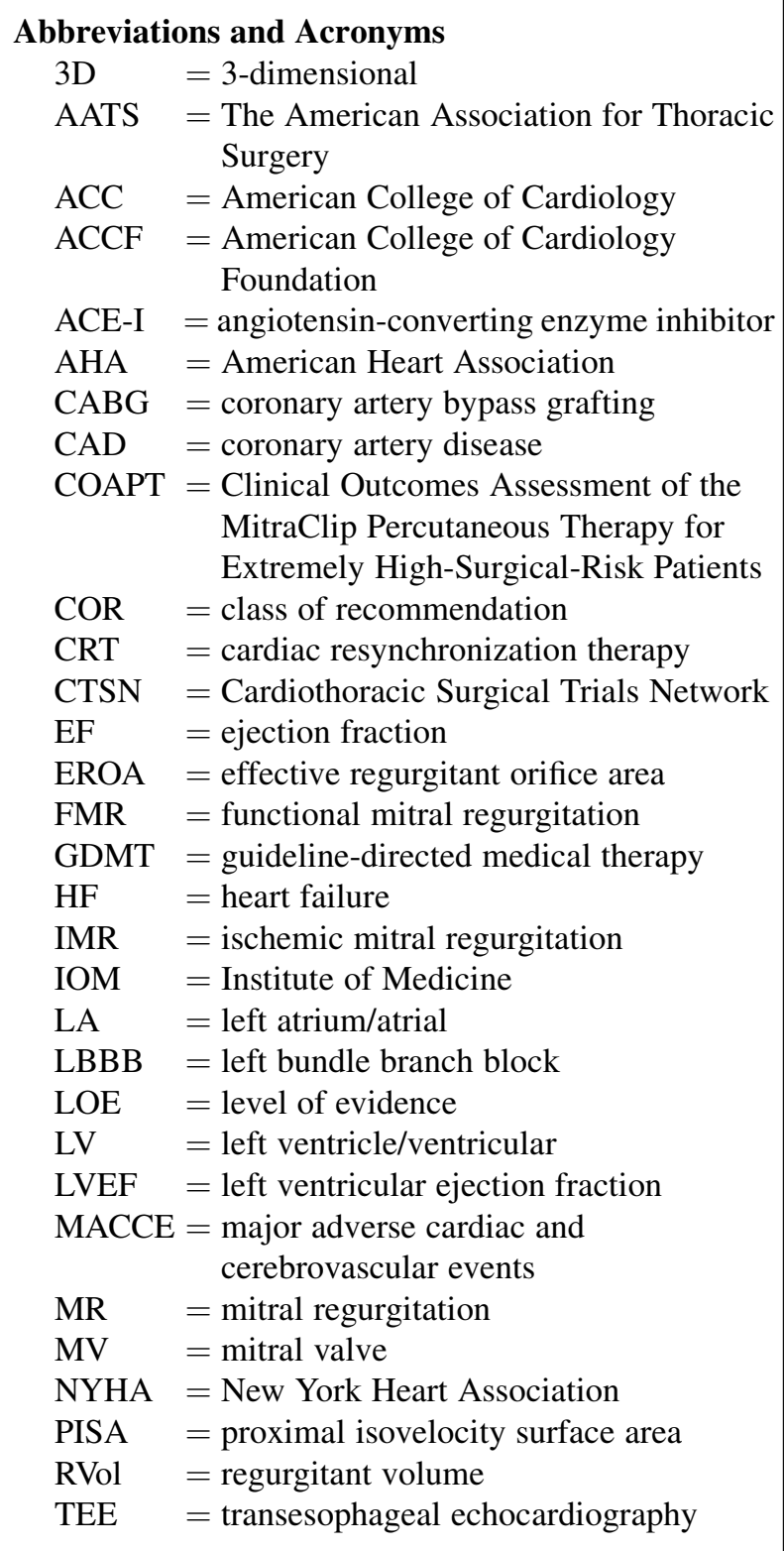

MV Replacement in IMR. . . . . . . . . . . . . . . . .e110 SECTION VI: Percutaneous Transcatheter Mitral Repair

Guidelines for Treatment of IMR . . . . . . . . e110

The MitraClip Procedure . . . . . . . . . . . . . e111

MitraClip Data in FMR . . . . . . . . . . . . . . . e111

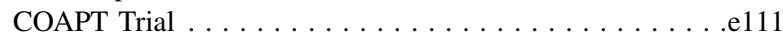

Heart Team Assessment. . . . . . . . . . . . . . . . .e112

SECTION VII: Conclusions . . . . . . . . . . . . . . . e112

References.......................... 112

\section{RATIONALE AND OBJECTIVES}

The objective of this project was to provide an update to the previously published consensus 2015 The American Association for Thoracic Surgery (AATS) evidence-based guidelines for the management of ischemic mitral regurgitation (IMR).

\section{METHODS OF REVIEW}

The AATS Guidelines Committee identified the management of IMR as a critical topic in cardiothoracic surgery suitable for the establishment of clinical guidelines. The Guidelines Committee selected Irving L. Kron, MD, as chair of the IMR working group and asked him to appoint an IMR Guidelines Working Group to develop evidence-based guidelines for the AATS Guidelines Committee. The chair assembled a multidisciplinary group of experts, including both adult cardiac surgeons and cardiologists, to perform comprehensive literature reviews and provide recommendations based on critical review of available evidence. The Writing Committee was tasked with grading the quality of the evidence supporting the recommendations and with assessing the relative treatment effect and anticipated risk for each recommendation. The level of evidence (LOE) was graded by the Writing Committee according to standards published by the Institute of Medicine (IOM; Table 1). The developed guidelines were based on the recommendations of the IOM 2011 Clinical Practice Guidelines We Can Trust: Standards for Developing Trustworthy Clinical Practice Guidelines (available at: http:// www.iom.edu/cpgstandards).

Scheduled teleconferences for the Writing Committee were conducted to organize the topics to be covered by the guidelines, review the literature review summaries, and to propose consensus guideline recommendations. The final recommendations of the Writing Group were prepared for presentation to the AATS Council through review of the final manuscript. All recommendations were subjected to a vote. Acceptance for the final document required greater than $75 \%$ approval for each recommendation and assigned LOE. The processes used followed the recommendations of the IOM, but extensive consultation with all other stakeholders, including patients, was not performed. Instead, the AATS Guideline Writing Committee attempted to develop timely recommendations in a field undergoing dynamic change and provide guidance to clinicians by using the best-available information and/or expert consensus opinion when the quality of the evidence was limited or discordant. The Guidelines were prepared for publication in The Journal of Thoracic \& Cardiovascular Surgery.

\section{SECTION I: INTRODUCTION-LIMITATION TO IMR GUIDELINES}

The 2016 Update to the AATS Consensus Guidelines on Ischemic Mitral Valve Regurgitation were developed based on the recently published 2-year results of 2 landmark randomized clinical trials, ${ }^{1,2}$ meta-analyses and large observational studies, as well as the expert opinion of the Writing Committee that have emerged since the original publication of our 2015 AATS Consensus Guidelines on IMR. ${ }^{3}$

Significant advances have been made in the treatment of ischemic cardiomyopathy, although controversy remains concerning the best management strategy for secondary mitral regurgitation (MR) in this population. Because of the relatively limited evidence base, American College of Cardiology (ACC)/American Heart Association (AHA) and European Society of Cardiology guidelines for the management of patients with valvular heart disease discuss treatment strategies for IMR only briefly and lack surgical clarity. ${ }^{4,5}$ In an effort to better define surgical definitions and strategies, the AATS appointed a Writing Committee to create this complementary Guideline consensus 
document, which outlines the optimal surgical management of patients with IMR.

The AATS Writing Committee for the Consensus Guidelines for Ischemic Mitral Valve Regurgitation realized that providing such guideline recommendations would be difficult. At one time, it was felt that this would be an easy problem to define and treat; however, as new knowledge has become available, treatment choices and timing of intervention have become less clear. Targeted clinical trials have investigated these subjects and have resulted in conclusions that contradict traditional surgical decision making.

IMR is a disease of the left ventricle (LV). The valve, by definition, is normal but leaks as the result of ventricular mechanisms. The regurgitation can be quite dynamic. We all have witnessed patients who have progressed from minimal to severe regurgitation during the same hospitalization. The dynamic nature of IMR mostly is related to loading conditions but also can reflect ongoing ischemia. Treatment options can be difficult because these patients often are fragile with several comorbidities. In addition, repair methods that have been used traditionally are somewhat limited. They work in one plane and often fail to address issues with the subvalvular apparatus. Finally, most of the studies that examine IMR are limited by their observational nature, selection and treatment biases, surrogate endpoints, and short-term outcomes, including many of the studies cited in this set of guidelines. Recent randomized studies have reported 2-year results but not 5- or 10-year results. ${ }^{1,2}$ Mortality rates for patients with moderate or severe IMR are high, but improving - compared with historical controlswith advances in medical and surgical therapies. These consensus guidelines reflect the efforts of a panel of experts, using expert opinion when necessary, and are based on what is known at this moment in time. There is no doubt that the consensus guidelines will continue to evolve as longer-term data become available.

\section{SECTION II: DEFINITIONS AND MECHANISMS OF IMR \\ Definition of IMR}

Using the construct of Carpentier's pathophysiologic triad, ${ }^{6}$ it is possible to strictly define IMR on the basis of etiology, lesion, and dysfunction. The etiology in this process is ischemic heart disease, and by definition patients must have evidence of coronary artery disease (CAD) and previous myocardial infarction, with either regional or global dysfunction or dilatation (remodeling) of the LV. The primary lesion in IMR is leaflet tethering, which results from ventricular remodeling associated with an ischemic insult. Posterolateral and apical displacement of the papillary muscles, which correlates with a measurable "tethering distance," ${ }^{, 78}$ leads to apical tenting and restriction of the free margin of the leaflets and poor leaflet coaptation. Tethering of secondary chordae can lead to a "seagull" deformation of the anterior leaflet, which has been targeted in certain repair series. ${ }^{9}$ Although both papillary muscles typically are displaced, the posterior papillary muscle group usually predominates, which leads to more aggressive tethering of the "P3" leaflet segment. This is particularly true in posterior infarction related to the posterior descending artery distribution. In such circumstances, the MR jet usually is eccentric and posteriorly directed along the P3 area, which selectively is restricted. ${ }^{7,8}$ In contrast, left anterior descending artery infarction tends to result in more global remodeling involving both papillary muscles and more diffuse leaflet tethering involving all segments, leading to large central jets of MR..$^{10,11}$

Although annular dilatation and distortion often accompany ventricular remodeling, papillary muscle displacement, and leaflet tethering, it usually is an associated as opposed to a primary lesion in IMR. The degree of annular dilatation is much less in patients with IMR than in those with degenerative $\mathrm{MR},{ }^{12}$ which is one of the reasons that "downsizing" of the annuloplasty repair is recommended to address leaflet tethering in IMR. The posterior-medial portion of the annulus most often is affected, although the anterior annulus is now recognized to flatten and elongate in IMR as well. ${ }^{13,14}$ Posterior infarction tends to lead to septal-lateral dilatation along the A1-P3 axis, whereas anterior infarction leads to more global dilatation, leading to symmetric and circular enlargement of the annulus. ${ }^{15}$

Although the majority of patients with IMR present with remote infarction and ventricular remodeling with leaflet tethering, acute ischemia with regional wall motion abnormalities also can lead to leaflet tethering in some patients. In this setting, revascularization alone may lead to resolution of wall motion abnormalities and improvement in IMR. Papillary muscle elongation with leaflet prolapse is a rare cause of MR related to myocardial infarction, and it should be distinguished generally from more typical IMR with restricted leaflet motion. Isolated basilar infarction can lead to annular dilatation without leaflet tethering, and this is perhaps the most favorable dysfunction associated with IMR.

\section{SECTION III: IMAGING OF IMR}

\section{Imaging Features of IMR}

Posterolateral displacement of the papillary muscles leads to stretching of the chordae tendineae and increased tethering forces on the mitral valve (MV) leaflets. ${ }^{16-18} \mathrm{~A}$ key imaging feature of IMR is the presence of mitral leaflet apical tethering where the coaptation point is displaced apically (Figure 1). Because of tethering from the chords, leaflets are unable to coapt normally in the annular plane, resulting in incomplete closure (Figure 2). Leaflet morphology is normal in IMR, and it is important to exclude structural abnormalities such as ruptured chords or flail leaflet that would imply primary pathology. Because of the decreased surface area of the posterior leaflet relative 
TABLE 1. Definitions used for COR and LOE

\begin{tabular}{|c|c|c|c|}
\hline \multicolumn{4}{|c|}{ Applying COR and LOE } \\
\hline Class I & Class IIa & Class IIb & $\overline{\text { Class III }}$ \\
\hline $\begin{array}{l}\text { Procedure/treatment } \\
\text { SHOULD be } \\
\text { performed/admini } \\
\text { stered }\end{array}$ & $\begin{array}{l}\text { Additional studies } \\
\text { with focused } \\
\text { objectives needed IT } \\
\text { IS REASONABLE } \\
\text { to perform } \\
\text { procedure/administer } \\
\text { treatment }\end{array}$ & $\begin{array}{l}\text { Additional studies } \\
\text { with broad objectives } \\
\text { needed; additional } \\
\text { registry data would } \\
\text { be helpful. } \\
\text { Procedure/treatment } \\
\text { MAY BE } \\
\text { CONSIDERED }\end{array}$ & $\begin{array}{l}\text { Risk } \geq \text { benefit } \\
\text { No additional studies } \\
\text { needed. } \\
\text { Procedure/treatment } \\
\text { should NOT be } \\
\text { performed/administere } \\
\text { SINCE IT NOT } \\
\text { HELPFUL AND } \\
\text { MAY BE } \\
\text { HARMFUL }\end{array}$ \\
\hline $\begin{array}{l}\text { analyses. Multiple (3 } \\
\text { and magnitude of ef }\end{array}$ & $\begin{array}{l}\text { 5) population risk } \\
\text { ct. }\end{array}$ & valuated. Genera & $\begin{array}{l}\text { istency of direction } \\
\text { isten or meta- }\end{array}$ \\
\hline $\begin{array}{l}\text { Level B: Recomm } \\
\text { randomized studie }\end{array}$ & $\begin{array}{l}\text { ndation based on evid } \\
\text { Limited (2-3) popula }\end{array}$ & $\begin{array}{l}\text { from a single random } \\
\text { isk strata evaluated. }\end{array}$ & ed trial or non- \\
\hline$V$ & & 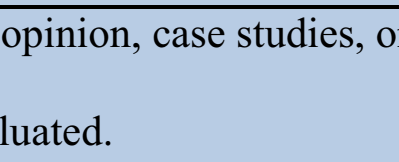 & \\
\hline
\end{tabular}

COR, Class of recommendation; $L O E$, level of evidence. Adapted from Nishimura and colleagues.

to the anterior leaflet, tethering of the posterior leaflet often is greater, resulting in asymmetric tethering and coaptation and an eccentrically directed MR jet (Figure 3). Tethering of basal or strut chordae can lead to a bend in the body of the anterior leaflet, contributing to tethering and impaired coaptation (Figure 4).

There are a number of methods to quantify the degree of tethering. The most common is a simple area measurement 


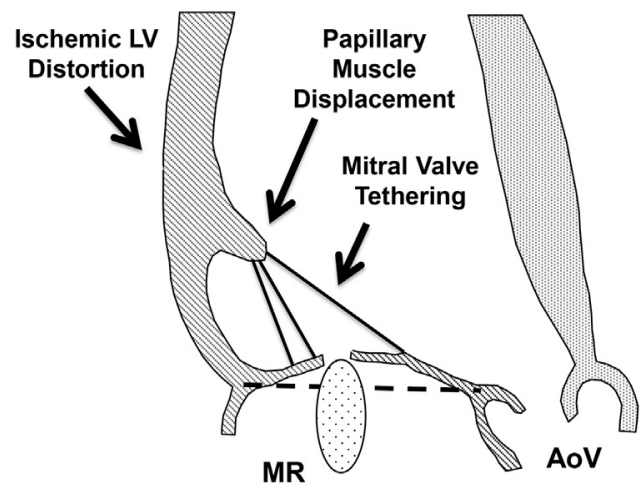

FIGURE 1. Illustrated mechanism of ischemic mitral regurgitation. Apically displaced leaflet coaptation with restricted leaflet closure results in mitral regurgitation. $L V$, Left ventricular; $M R$, mitral regurgitation; AoV, aortic valve.

from the leaflets to the annular plane (tenting area), typically performed at midsystole where the area is at a minimum. Another measure is coaptation height or depth, which measures the maximal distance from the leaflet tips to the annular plane and appears to correlate with the presence and severity of IMR. ${ }^{19}$ More recently, 3-dimensional (3D) echocardiography has been applied to quantify leaflet tethering by measuring the tethering distance from papillary muscle tip to the mitral annulus and measurement of tenting volume (volume from leaflets to annular plane) and may provide an additional index of tethering (Figure 5). ${ }^{20}$

LV remodeling can be relatively focal with ventricular distortion limited to the inferior-posterior segment such as occurs in a basal-inferior aneurysm (Figure 6), or the remodeling can be diffuse with global LV dilation and a spherically shaped $\mathrm{LV}^{21}$

\section{Grading of MR: How to Do It}

General considerations. Echocardiography is the primary imaging modality used to grade MR. It is noninvasive, accessible, and cost-effective. Grading of MR should not rely on a single parameter but rather an integrative approach incorporating multiple quantitative and qualitative echocardiographic measures.

The grading of MR is based on Doppler techniques and supportive echocardiographic data, which will be discussed in this section.

\section{Doppler Methods}

Doppler techniques are based on evaluation of the flow dynamic pattern of the MR jet. The MR jet consists of 3 parts: (1) the proximal isovelocity surface area (PISA), which is the zone of flow convergence as it approaches the mitral orifice; (2) The vena contracta, which is the width of the MR jet as it goes through the orifice; and (3) the distal jet, which is the MR flow as it exits the orifice (Figure 7). Distal jet area method. The distal jet area method involves measuring the maximal MR jet as it exits the leaflet level and enters the left atrium (LA). The maximal jet area is traced in the apical 4- and 2-chamber views and an average of the areas calculated. The jet area is normalized commonly to the LA area and expressed as a ratio or percentage of the maximal LA area measured in the same frame (Figure 7). ${ }^{22,23}$ MR jet area/LA area ratios of $<20 \%$ correspond to mild MR, whereas ratios of $>40 \%$ correspond to severe MR (Table 2). The distal jet area method is simple and commonly used as a semiquantitative assessment of MR. This method, however, is influenced by both technical and physiological factors. Common technical factors involve ultrasound machine settings such as gain and Nyquist limits, which influence the size of the distal jet. Physiological factors that impact the distal jet are the loading conditions represented by systemic blood pressure and volume status.

Eccentric MR jets can be "absorbed" by the LA wall, underestimating the degree of MR. Eccentric jets in which the MR jet travels out of the plane of the ultrasound beam

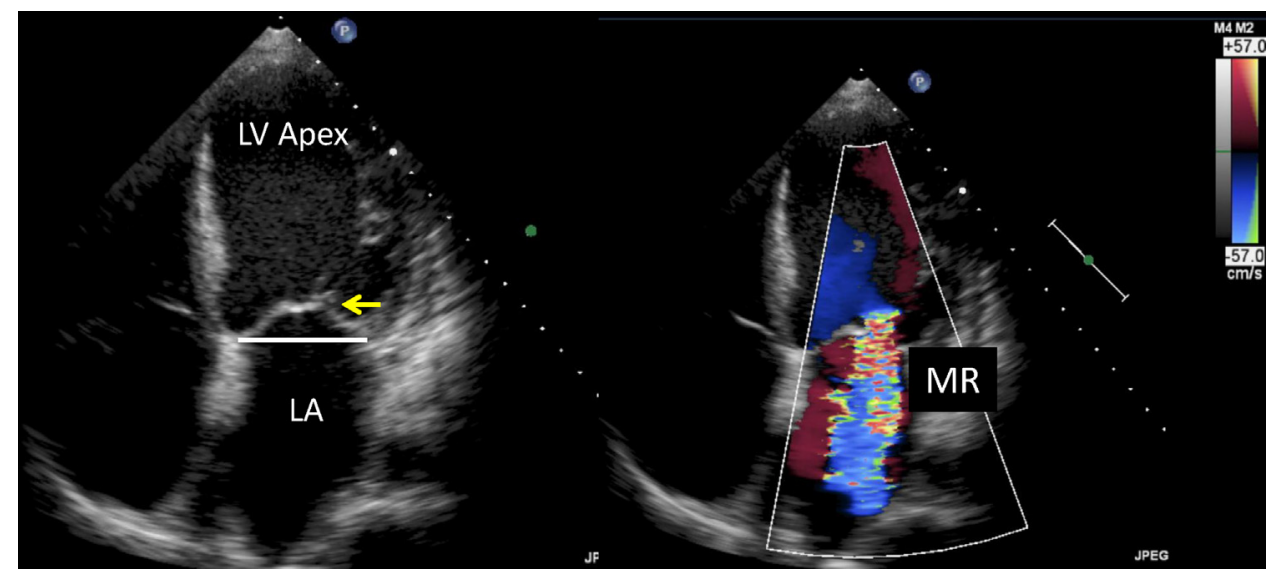

FIGURE 2. Transthoracic echocardiography demonstrating reduced mitral leaflet coaptation in the annular plane, resulting in incomplete leaflet closure and mitral regurgitation. $L V$, Left ventricular; $L A$, left atrial; $M R$, mitral regurgitation. 


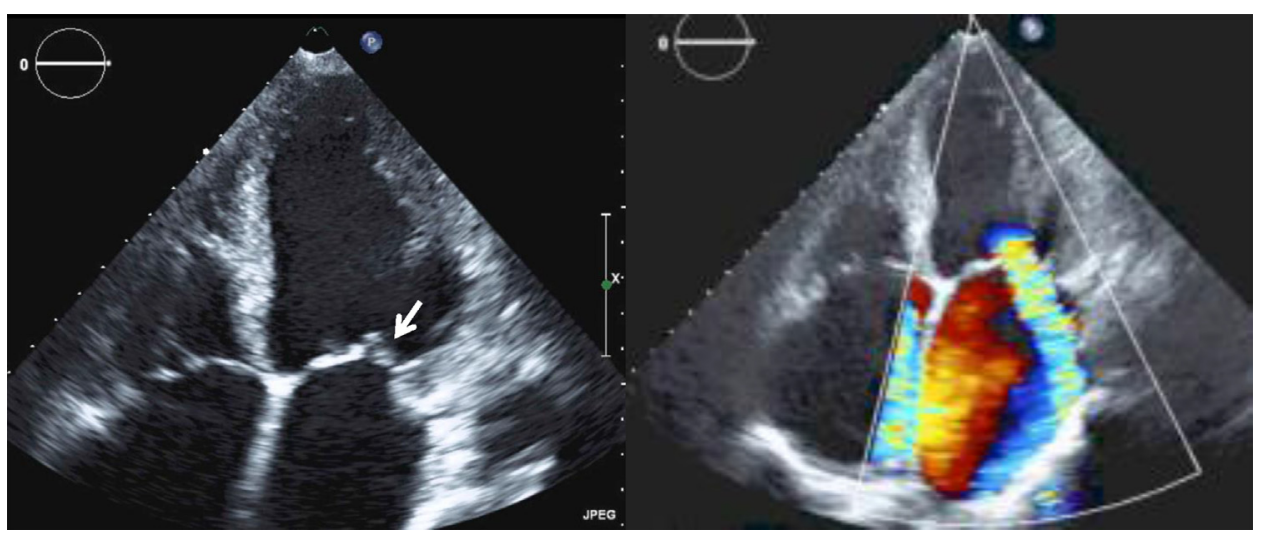

FIGURE 3. Transthoracic echocardiography demonstrating decreased surface area of the posterior leaflet relative to the anterior leaflet and tethering of the posterior leaflet, resulting in asymmetric coaptation with an eccentrically directed mitral regurgitant jet. Arrow points to posterior leaflet.

also will be missed or underestimated. Because of the limitations with eccentric jets, the jet area method is best applied to centrally directed jets. ${ }^{24}$

Vena contracta width. The vena contracta is the narrowest portion of the MR jet and provides a simple linear measurement of the proximal MR jet. ${ }^{25}$ The vena contracta width is measured along the anterior-posterior plane of the mitral orifice and ideally should be measured in the parasternal long-axis view (Figure 8). If the parasternal long-axis view is technically inadequate, an apical long-axis view can be used. Measurement of vena contracta width should be avoided in the 2-chamber view (medial-lateral dimension) because this view images the MR proximal jet along the coaptation line.

Vena contracta measurements $<3 \mathrm{~mm}$ correspond to mild MR, 0.3-0.69 to moderate MR, and $\geq 0.7$ to severe MR (Table 2). Vena contracta is a clinically useful, direct semiquantitative measure of MR severity that can be obtained

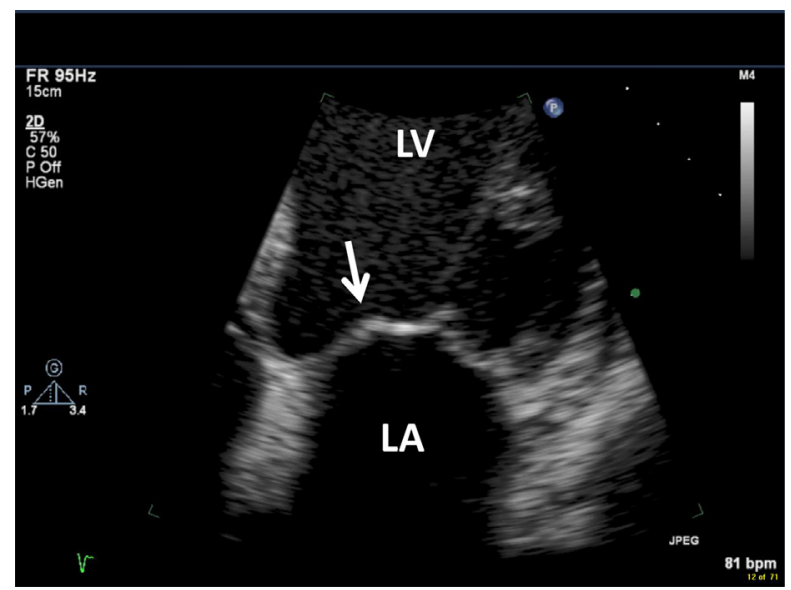

FIGURE 4. Transthoracic echocardiography demonstrating tethering of the basal or strut chordae that can result in a bend in the body of the anterior leaflet, further contributing to mitral leaflet tethering and impaired coaptation. $L V$, Left ventricle; $L A$, left atrium. simply. In addition, the vena contracta is less influenced by physiologic loading conditions and easier to measure in eccentric jets compared with distal jet area and hence may be more reproducible. ${ }^{24}$

The reference range of vena contracta width is narrow, and small differences in width can make a large impact on MR grading. Therefore, it is important to maximize the sector (zoom) and depth for optimal color Doppler resolution.

PISA method. The PISA method is a quantitative Doppler measure of the effective regurgitant orifice area (EROA) and regurgitant volume (RVol). This method is based on the fluid dynamic principle that as flow approaches a circular finite orifice, it forms concentric hemispherical shells with gradually decreasing surface area and increasing

\section{Tenting Volume by 3D}

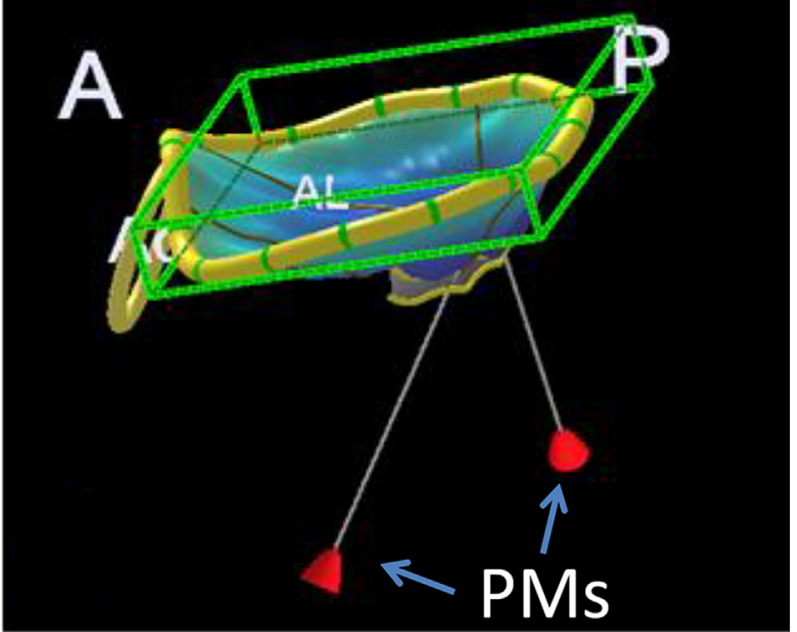

FIGURE 5. Illustration of measurement of tenting volume used in $3 \mathrm{D}$ echocardiography. $3 D$, 3-Dimensional; $A$, anterior; $P$, posterior; $A L$, anterolateral; PMs, posteromedial. 


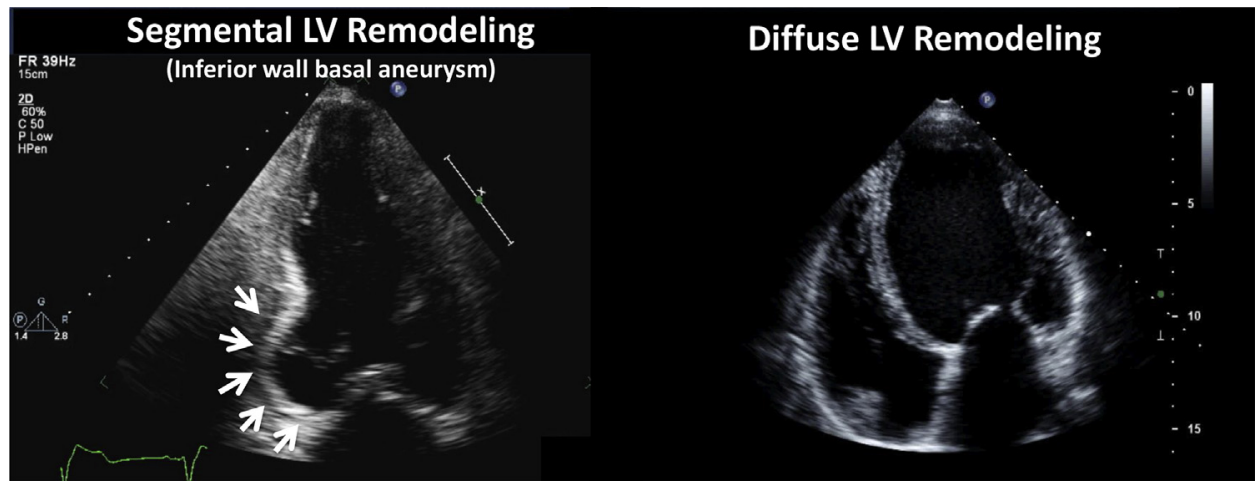

FIGURE 6. Transthoracic echocardiography demonstrating LV remodeling as a result of ischemic mitral regurgitation. $L V$, Left ventricular.

velocity. ${ }^{26-28}$ This principle is applied to MR flow, where the PISA region is the hemispheric shell that forms proximal to the mitral leaflets on the LV side and the finite orifice is the MR orifice at the level of the leaflets. The flow rate of the hemispheric shell equals the MR rate at the orifice by the conservation of mass principle. Assuming a hemispheric shape for the isovelocity shells, then flow rate $=$ surface area of a hemisphere $=2 \pi r^{2} \times$ aliasing velocity, where $r$ is the radius of the hemispherical shell. The EROA and RVol can be derived from the flow rate with the following formulas: regurgitant orifice area $=\mathrm{MR}$ flow rate/peak MR velocity by color wave (Figure 9). $\mathrm{RVol}=\mathrm{EROA} \times$ time velocity integral $(\mathrm{MR}$ jet $)$.

Accuracy and reproducibility of the PISA method are highly dependent on attention to technique. The PISA

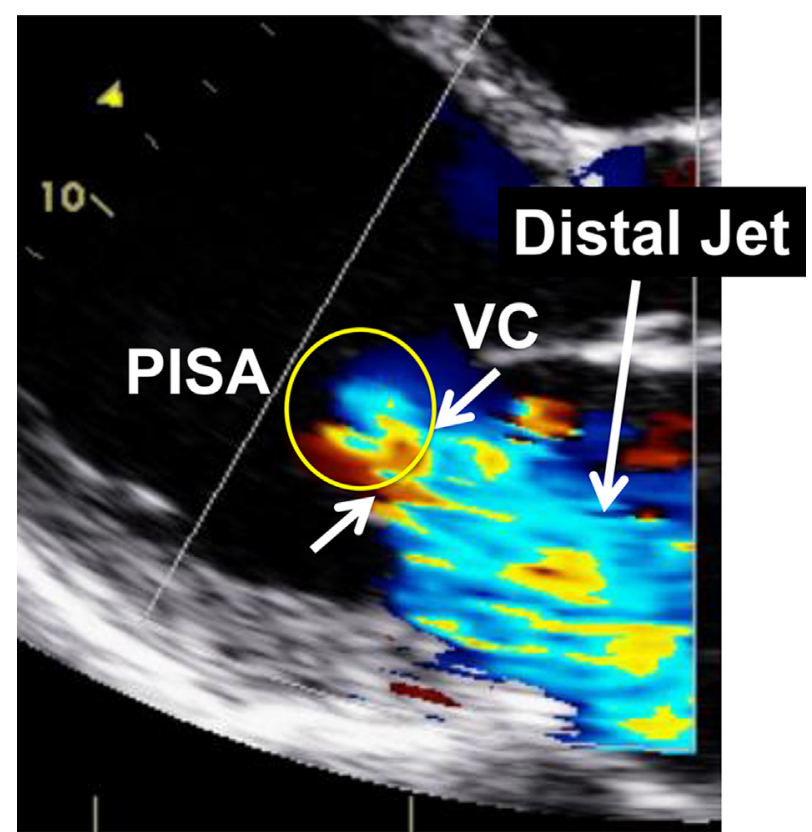

FIGURE 7. Measurement of distal jet area by Doppler echocardiography. $P I S A$, Proximal isovelocity surface area; $V C$, vena contracta. region should be magnified with sector and depth optimized for color Doppler resolution. Measurement of PISA should be aligned parallel to flow direction because this optimizes Doppler resolution. To optimize measurement of the PISA radius ( $r$ ), the baseline of the Nyquist limit is shifted toward the direction of the MR flow. Nyquist limit ranges between 30 and $40 \mathrm{~cm} / \mathrm{s}$ are optimal for PISA radius measurement.

Factors influencing the PISA method. In theory, the PISA method provides an accurate, quantitative measure of MR; however, there are technical and practical aspects to the PISA method that limit clinical applicability. Eccentric MR jets can distort the PISA region as the result of constraint from the LA wall or mitral leaflet, resulting in a falsely increased radius ( $r$ ) and overestimation of the EROA. ${ }^{29}$ An angle correction factor can be applied to the

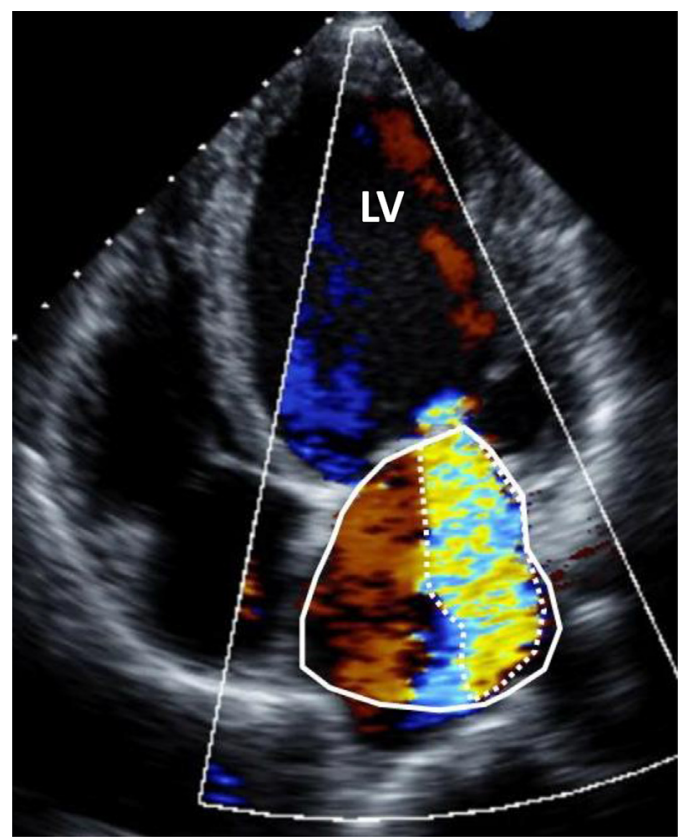

FIGURE 8. Measurement of vena contracta in apical long-axis view by transthoracic echocardiography. $L V$, Left ventricle. 
TABLE 2. Integrative method of IMR grading

\begin{tabular}{llll}
\hline Parameter & \multicolumn{1}{c}{ Mild } & Moderate & \multicolumn{1}{c}{ Severe } \\
\hline 1. Doppler measures (semiquantitative and quantitative) \\
EROA, cm ${ }^{2}$ & $<0.2$ & $\geq 0.2 \mathrm{vs} \geq 0.4$ \\
VC width, cm & $<0.3$ & $0.3-0.69$ & $\geq 0.7$ \\
Jet/LA area & $<20 \%$ & $20 \%-39 \%$ & $\geq 40 \%$ \\
MR reg. volume $\quad<30 \mathrm{~mL}$ & $30-59 \mathrm{~mL}$ & $\geq 30 \mathrm{vs} 60 \mathrm{~mL}$ \\
2. Supportive criteria & & \\
E-wave velocity size & & \\
Pulmonary vein flow reversal & \\
Density of CW MR jet \\
Chamber size
\end{tabular}

EROA, Effective regurgitant orifice area; $V C$, vena contracta; $L A$, left atrial; $M R$, mitral regurgitation; $C W$, color wave.

surface area calculation but is not used widely because of the difficulty in measuring the angle and the additional complexity this adds to PISA calculation. Importantly, although eccentric jets do occur with ischemic MR as the result of asymmetric tethering of the leaflets, the eccentricity of the jet typically is not enough where distortion of the PISA zone occurs.

An important limitation of the PISA method for calculating EROA is that the contour of the PISA region is not always hemispherical but often hemielliptical, ${ }^{30,31}$ especially in IMR, where the mitral orifice shape is often noncircular. This has the effect of underestimating the EROA when the standard hemispherical assumption used in PISA method is applied. 3D echo-guided measurement of the vena contracta area, which is a direct measure of the effective orifice area, avoids the inherent underestimation of EROA by the 2-dimensional PISA method. ${ }^{32,33} \mathrm{~A}$ number of studies have examined and validated 3D vena contracta area to other methods of MR quantitation, including cardiac magnetic resonance, and 3D-measured vena contracta area can provide an important alternate method for quantitating MR, especially in cases in which there are discrepant data. ${ }^{34-36}$ The bias for PISA to underestimate severity of MR in patients with secondary MR (including IMR) may explain partly the finding that lower thresholds for EROA (compared with EROA thresholds used in patients with primary MR) are associated with worse prognosis in such patients. ${ }^{32}$

Different reference values for EROA based on etiology of MR. Recent valve guidelines have proposed different cutoff values for mitral EROA and RVol for moderate and severe MR depending on etiology. Severe primary MR is defined by an EROA of $\geq 0.4 \mathrm{~cm}^{2}$ and $\mathrm{RVol} \geq 60 \mathrm{~mL} /$ beat; severe secondary MR (including IMR) is defined by an EROA $\geq 0.2 \mathrm{~cm}^{2}$ and $\mathrm{RVol} \geq 30 \mathrm{~mL} /$ beat, in keeping with the results of natural history studies linking these parameters with outcomes. ${ }^{37,38}$ There are important limitations to the use of a lower EROA cutoff value for IMR. First, prognostic data are based on retrospective analyses with potential selection bias. Second, EROA and RVol values are dependent on LV volumes, which can account for lower EROA values in IMR. Third, a hemispherical assumption will underestimate EROA and RVol in IMR. Finally, EROA and RVol calculations obtained by the PISA method are difficult to reproduce reliably across laboratories. ${ }^{32}$

Supportive criteria. A tall E-wave peak velocity from the mitral inflow pattern is supportive of severe MR. A peak Ewave velocity of $>1.2 \mathrm{~m} / \mathrm{s}$ is suggestive of severe MR. A dense continuous-wave Doppler profile provides important complementary data for severe MR. It is important to align the transducer parallel to the MR flow profile to allow for accurate continuous-wave Doppler assessment. Systolic blunting of the pulmonary vein systolic wave is consistent with at least moderate MR. Systolic pulmonary vein flow reversal is a specific, although not sensitive, sign of severe $\mathrm{MR}^{24}$

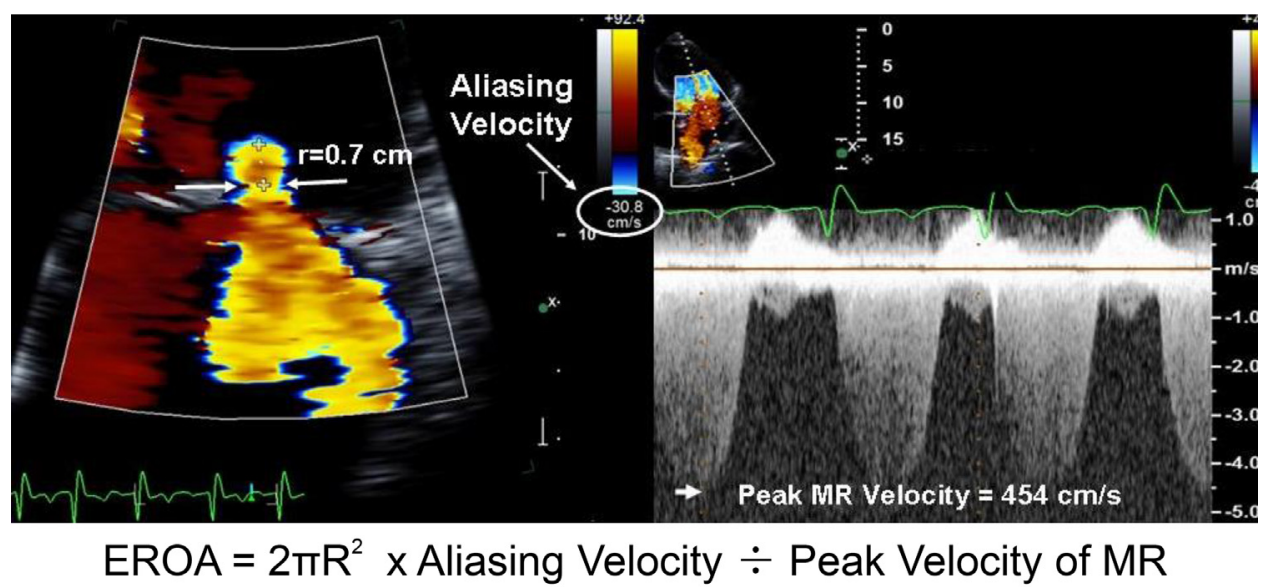

FIGURE 9. Calculation of mitral valve regurgitant orifice area (EROA) using the PISA method. EROA, Effective regurgitant orifice area; $M R$, mitral regurgitation. 
The Doppler echocardiographic examination also should include assessment of LV size and function, LA size, description of any structural abnormalities of the MV leaflets, chordae and papillary muscles, an estimate of pulmonary artery systolic pressure, and survey of other valvular heart disease (eg, tricuspid regurgitation). With few exceptions, severe MR is accompanied by both LA and LV enlargement.

Transesophageal echocardiography (TEE) assessment of MR severity. The severity of MR is impacted by loading conditions, and this is important to acknowledge during the intraoperative assessment. Clinical decision making based on MR severity assessed in the operating room is best avoided, because the severity of MR often is less than in other clinical settings because of the ventricular unloading that occurs with anesthesia. ${ }^{39}$ Grading of MR ideally should be assessed with patient awake, alert, and medically stable, although the dynamic nature of IMR can make assessment challenging. In addition, the methods for grading MR using TEE are less validated than with transthoracic echocardiography imaging. In cases in which preoperative assessment of MR is not available, intraoperative manipulation of volume and/or afterload to mimic other physiologic settings may be performed. ${ }^{40}$

\section{Putting It All Together: Importance of the Integrative Method}

It is important to emphasize that an integrative approach should be used to grade MR with incorporation of multiple Doppler parameters and supportive criteria as noted previously. ${ }^{32,37,38}$ This has the advantage of using the strengths of each Doppler technique while avoiding reliance on a single parameter, thereby minimizing the limitations inherent in each.

\section{SECTION IV: INDICATIONS FOR SURGERY IN PATIENTS WITH IMR}

There is a strong association between the severity of secondary MR, including IMR, and all-cause mortality, as well as with hospitalizations for heart failure (HF). Among 303 patients postmyocardial infarction, MR was present in 194 patients $(64.0 \%)$ and was a significant independent predictor of long-term mortality (relative risk, 1.88; $95 \%$ confidence interval 1.23-2.86; $P=.003){ }^{41}$ In a study from the Duke Cardiovascular Databank, angiographic $3+/ 4+$ MR was present in $29.8 \%$ of 2057 patients with HF with a left ventricular ejection fraction (LVEF) $<40 \%$ and was an independent predictor of 5year mortality (adjusted HR 1.23; 95\% confidence interval 1.13-1.34) ${ }^{42}$ Whereas the presence of severe secondary MR predicts poor prognosis in patients with $\mathrm{LV}$ dysfunction and HF, studies to date have not shown that surgical correction improves survival.

\section{Treatment of IMR}

The goals of therapy in patients with IMR should be to improve symptoms and quality of life, reduce hospitalization for HF, and improve survival. Therapies shown to be most effective are those directed at the underlying LV dysfunction, including guideline-directed medical therapy (GDMT) for HF with reduced ejection fraction (EF) and cardiac resynchronization therapy (CRT) when appropriate. ${ }^{43}$ Coronary revascularization should be performed in patients with ischemia and myocardial viability. The role of surgical MV repair or replacement is to interrupt the vicious cycle of LV volume overload, which leads to further LV remodeling and mitral annular dilatation with worsening MR, fulfilling the dictum that "MR begets MR." Medical therapy. All patients with IMR should receive GDMT for the long-term management of CAD and, when present, LV systolic dysfunction and HF. Medical interventions include:

- aspirin;

- a P2Y12 inhibitor if percutaneous coronary intervention has been performed;

- high-intensity statin therapy;

- beta-blockers (for at least 3 years after myocardial infarction or indefinitely in presence of residual angina, HF, hypertension, arrhythmia, or other indication);

- an angiotensin-converting enzyme inhibitor (ACE-I) (or angiotensin receptor blocker if the patient is unable to tolerate ACE-I);

- consideration of sacubitril/valsartan, if indicated; and

- eplerenone or spironolactone (as dictated by LVEF, HF status, or the presence of diabetes).

GDMT is first-line treatment for patients with secondary MR. ${ }^{4}$ Unfortunately, morbidity and mortality of patients with LV dysfunction and secondary MR remain high despite GDMT. Among 404 patients treated with GDMT, 4 -year cardiac mortality rates were $43 \%$ and $45 \%$ with moderate and severe MR respectively, compared with only $6 \%$ for patients with mild MR $(P=.003) .{ }^{44}$ In this same study, moderate or severe MR also was an independent predictor of new-onset HF in patients with ischemic LV dysfunction (relative risk, 3.2; 95\% CI 1.9-5.2, $P=.0001$ ).

Beta-blockers and ACE-I are recommended for all patients with LV systolic dysfunction and secondary MR. There is increasing emphasis on the preferred use of sacubitril/valsartan for eligible patients. GDMT may reduce the severity of MR in many patients. In small, nonrandomized studies, the use of carvedilol in patients with HF and secondary MR was associated with improved LV systolic function and reduced MR severity lasting 6 to 12 months. ${ }^{45,46}$

Resynchronization therapy for secondary MR. CRT is a well-established treatment for HF in selected patients with LV dyssynchrony and wide QRS. CRT is recommended 
(class of recommendation [COR] I) for patients in sinus rhythm with New York Heart Association (NYHA) Class II-IV symptoms on GDMT with LVEF $\leq 35 \%$, left bundle branch block (LBBB), and QRS duration $\geq 150$ milliseconds. CRT can be useful in patients with LVEF $\leq 35 \%$, sinus rhythm, and non-LBBB pattern with QRS duration $\geq 150$ milliseconds and in those with LBBB and QRS duration 120 to 149 milliseconds (COR IIa). ${ }^{43}$ Randomized trials have demonstrated improvements in both survival and rates of rehospitalization for HF in patients treated with CRT with or without a defibrillator, ${ }^{47}$ along with reductions in LV end-diastolic and end-systolic dimensions and improved LVEF. The effect of CRT on secondary MR is inconsistent, although most studies have shown a reduction in overall severity of MR with restoration of synchronous ventricular contraction and reverse LV remodeling. In the sham-controlled MIRACLE (Multicenter InSync Randomized Clinical Evaluation) trial of 450 patients with NYHA class III/IV HF with LVEF $\leq 35 \%$ and QRS duration $\geq 130$ milliseconds, CRT resulted in marked reductions in LV end-diastolic and systolic volumes, improved LVEF, and sustained reductions in MR (as assessed by the relative size of the mitral jet area in the LA). ${ }^{47}$

Unfortunately, severe secondary MR improves in no more than one half of patients after CRT, although such improvement does identify a cohort with an improved prognosis. In a study of 85 patients with HF with $3+/$ $4+$ secondary MR, MR grade at 6 months was reduced after CRT in $42(49 \%)$. Two-year survival was $92 \%$ in MR responders versus $67 \%$ in nonresponders $(P<.001) .{ }^{48,49}$

Use of implantable cardiac defibrillators is recommended for primary prevention of sudden cardiac death in patients with previous myocardial infarction and LV systolic dysfunction as defined in current guidelines (ACC/AHA/ Heart Rhythm Society 2008 guideline).

Coronary revascularization. The need for coronary revascularization should be assessed with clinical evaluation and noninvasive diagnostic testing, which may involve the use of myocardial perfusion imaging, stress echocardiography, or cardiac magnetic resonance imaging. A heart team approach is considered essential for appropriate decision making regarding the optimal revascularization strategy in patients with complex multivessel CAD. Many patients with moderate IMR will experience a sustained reduction in severity of MR with revascularization alone. Identification of these patients preoperatively, however, has not been standardized, and surgical decision making in this setting varies across operators and institutions. Recommendations for surgical myocardial revascularization in patients IMR are discussed in more detail in the section to follow.

Indications for surgery in IMR. Surgical options for secondary MR include surgical MV repair or replacement, mechanical LV-assist devices, and orthotopic heart transplantation. Although secondary MR can be corrected acutely by MV surgery, it has never been demonstrated clearly that reducing or eliminating MR alters the natural history of the underlying LV disease or improves survival. ${ }^{16,49-51}$ Moreover, whether the response to surgery is different in patients with IMR compared with secondary MR of nonischemic origin also has not been established.

Thus, the indications for surgery for patients with IMR are more conservative than those pertaining to patients with primary, degenerative MR because in large measure of the recognition that intermediate- and long-term outcomes inextricably are linked to the underlying LV dysfunction and adverse remodeling. Two landmark randomized controlled trials conducted by the Cardiothoracic Surgery Trials Network (CTSN) evaluated surgical results for both severe and moderate IMR. In the severe IMR (SMR) trial, MV repair was compared with chord-sparing MV replacement. Patients underwent coronary artery bypass grafting (CABG) as dictated by clinical, noninvasive, and angiographic findings. There were no differences at 1 year between the repair and replacement groups for the primary endpoint of LV end-systolic volume index, mortality, or the rate of major adverse cardiac and cerebrovascular events (MACCEs). ${ }^{52}$ The rate of postoperative moderate or severe MR at 1 year after MV repair was greater than appreciated previously $(32.6 \%$ with repair vs $2.3 \%$ for replacement, $P<.001)$. At 2 years, the significant excess rate of recurrent moderate or severe MR among repair patients was maintained and associated with greater rates of HF events and readmissions for cardiovascular causes, as well as with a trend toward reduced quality of life.

In the moderate IMR (MMR) trial, patients were randomized to $C A B G$ plus $M V$ repair or $C A B G$ alone. Although the performance of $\mathrm{MV}$ repair was significantly more effective than $\mathrm{CABG}$ alone at reducing or eliminating moderate IMR, there were no between-group differences at 1 year in LVESVI or rates of MACCEs. ${ }^{53}$ The addition of MV repair was associated with a greater number of early serious neurologic events $(P=.03)$ and supraventricular arrhythmias $(P=.03)$. At 2 years, no differences between groups emerged with respect to LV end-systolic volume index, mortality, or rates of MACCEs. Longer follow-up of patients after surgical treatment of IMR will reveal whether differences in rates of recurrent MR will become manifest in hard clinical endpoints such as death and hospitalization for HF.

In the 2012 European Society of Cardiology/EACT guidelines, MV repair for isolated, severe, secondary MR was given a class IIb (LOE C) recommendation, but only for patients at low surgical risk with LVEF $\geq 30 \% .{ }^{38}$ The 2014 AHA/ACC guidelines for the management of patients with valvular heart disease provide the following recommendations for surgery in patients with secondary MR. ${ }^{4}$ 
TABLE 3. Summary comparison of existing societal guidelines and AATS guidelines for the surgical treatment of IMR

\begin{tabular}{|c|c|}
\hline Existing societal guidelines & AATS guidelines \\
\hline $\begin{array}{l}\text { Moderate IMR } \\
\text { A. MV repair can be considered at time of } \\
\text { CABG (COR IIb, LOE B) } \\
\text { B. MV surgery can be considered at time of } \\
\text { other cardiac surgery (eg, AVR) (COR } \\
\text { IIb, LOE C) }\end{array}$ & $\begin{array}{l}\text { Moderate IMR } \\
\text { A. In patients with moderate IMR } \\
\text { undergoing CABG, MV repair with an } \\
\text { undersized complete rigid annuloplasty } \\
\text { ring may be considered (COR IIb, LOEB) }\end{array}$ \\
\hline $\begin{array}{l}\text { Severe IMR } \\
\text { A. MV surgery is reasonable at time of } \\
\text { CABG or other cardiac surgery (eg, } \\
\text { AVR) (COR IIa, LOE C) } \\
\text { B. MV surgery can be considered as an } \\
\text { isolated procedure for treatment of } \\
\text { significant heart failure symptoms that } \\
\text { persist despite guideline directed } \\
\text { medical therapy (COR IIb, LOE C) }\end{array}$ & $\begin{array}{l}\text { Severe IMR } \\
\text { A. MV replacement is reasonable in } \\
\text { patients with severe IMR who remain } \\
\text { symptomatic despite guideline directed } \\
\text { medial and cardiac device therapy, and } \\
\text { who have a basal aneurysm/dyskinesis, } \\
\text { significant leaflet tethering, and/or } \\
\text { severe LV dilatation (EDD }>6.5 \text { cm) } \\
\text { (COR IIa, LOE B) } \\
\text { B. MV repair with an undersized complete } \\
\text { rigid annuloplasty ring may be } \\
\text { considered in patient with severe IMR } \\
\text { who remain symptomatic despite } \\
\text { guideline directed medical and cardiac } \\
\text { device therapy and who do not have a } \\
\text { basal aneurysm/dyskinesis, significant } \\
\text { leaflet tethering, or severe LV } \\
\text { enlargement (COR IIb, LOE B) }\end{array}$ \\
\hline $\begin{array}{l}\text { MV replacement vs repair } \\
\text { Not available }\end{array}$ & $\begin{array}{l}\text { MV replacement vs repair } \\
\text { A. MVR for IMR is performed with } \\
\text { complete preservation of both anterior } \\
\text { and posterior leaflet chords (COR I, } \\
\text { LOE B) } \\
\text { B. MV repair for IMR is performed with } \\
\text { small, undersized complete rigid } \\
\text { annuloplasty ring (COR IIa, LOE B) }\end{array}$ \\
\hline
\end{tabular}

AATS, American Association for Thoracic Surgery; IMR, ischemic mitral regurgitation, $M V$, mitral valve; $C A B G$, coronary artery bypass grafting; $C O R$, class of recommendation; $L O E$, level of evidence; $A V R$, aortic valve replacement; $L V$, left ventricular; $E D D$, end diastolic dimension. 


\section{Moderate secondary MR}

a. MV repair may be considered at time of other cardiac surgery (including CABG) (COR IIb, LOE B).

2. Severe secondary MR

a. MV surgery is reasonable at time of other cardiac surgery (eg, CABG or aortic valve replacement) (COR IIa, LOE C).

b. MV surgery may be considered for severely symptomatic patients (NYHA III/IV) (COR IIb, LOE B).

\section{SECTION V: SURGICAL GUIDELINES FOR THE TREATMENT OF IMR \\ Repair Versus Replacement for Severe IMR}

The 2014 ACC/AHA guidelines do not specify whether MV replacement or repair should be performed in patients with severe secondary MR. This treatment choice is controversial because there is the perception that MV repair is associated with lower short- and intermediate-term morbidity and mortality ${ }^{54}$ but also with high recurrence rates of moderate/severe MR. ${ }^{55-57}$ This perception rests on a limited evidence base. The meta-analysis by Vassileva and colleagues ${ }^{54}$ is a compilation of retrospective and single-center observational studies. Moreover, very few patients in the studies reviewed had MV replacement with complete retention of both anterior and posterior chords, which is important for the preservation of LV function. Table 3 displays a summary of existing guidelines as well as those of this Writing Committee for the surgical treatment of IMR.

The decision between MV replacement or repair for severe IMR has been informed by a large, retrospective multicenter, propensity-matched study, as well as a multicenter randomized trial. ${ }^{52,58}$ Lorusso and colleagues ${ }^{58}$ reported no difference in short- or long-term mortality between patients treated with MV replacement versus repair. They also found no difference between surgical groups in late LV function, cardiac or valve-related death, or patient functional capacity. In this propensity-matched study, MV repair was the strongest predictor of the need for valve-related reoperation. In the aforementioned CTSN randomized study of severe IMR, recurrence of moderate or severe MR in surviving patients at 1 year was $32.6 \%{ }^{59}$ Interestingly, in a nonprespecified subgroup analysis of patients undergoing MV repair who did not develop moderate or severe recurrent MR, the degree of LV reverse remodeling exceeded that in patients who had undergone MV replacement.

In the CTSN severe IMR trial, the strongest predictor of recurrent MR in the repair group was the presence of a basal aneurysm or dyskinesis. ${ }^{59}$ Multiple singlecenter studies have reported independent predictors of recurrent IMR. These predictors fall into 2 categories: echocardiographic parameters of leaflet tethering and indices of LV remodeling. Studies have suggested that measures of increased tethering such as anterior and posterior leaflet angle, tethering length, tenting area, and height predict recurrent MR. Multiple groups point to the angle between the tip of the anterior leaflet and the annular plane as the most important predictor of MR recurrence. A significant anterior leaflet angle $>25^{\circ}$ was an independent predictor of MR recurrence and more important than any other measurement of tethering (eg, postleaflet angle, coaptation depth, tenting, etc) or indices of LV size (left ventricular end-diastolic diameter $>65 \mathrm{~mm}$ ) or sphericity. ${ }^{60-65}$ Other groups emphasize LV size, LV function, or degree of MR as key independent determinants of recurrent $\mathrm{MR},{ }^{60,66-73}$ whereas still others note the importance of both LV size and tethering as independent predictors. ${ }^{66,69}$

Patients identified to be at high risk for postoperative MR recurrence after simple annuloplasty repair or patients undergoing operations by less-experienced surgeons and hospitals in which annuloplasty alone is the only repair option offered should have MV replacement. More complex mitral repair operations that specifically address leaflet tethering through leaflet augmentation and/or papillary muscle repositioning have shown promising results but remain investigational and incompletely validated. ${ }^{9,64,74,75}$

\section{Patients With Severe IMR}

A. MV replacement is reasonable in patients with severe IMR who remain symptomatic despite guidelinedirected medical and cardiac device therapy and who have a basal aneurysm/dyskinesis, significant leaflet tethering, and/or severe LV dilation (end diastolic dimension $>6.5 \mathrm{~cm})\left(\right.$ COR IIa, LOE B). ${ }^{1,52}$

B. MV repair with an undersized complete rigid annuloplasty ring may be considered in patients with severe IMR who remain symptomatic despite guidelinedirected medical and cardiac device therapy and who do not have a basal aneurysm/dyskinesis, significant leaflet tethering, or severe LV enlargement (end diastolic dimension $>6.5 \mathrm{~cm})($ COR IIb, LOE B $){ }^{1,52}$

Long-term follow-up of surviving patients in the CTSN severe IMR Trial will be important to understand the clinical consequences of recurrent MR, as well as the durability of the results achieved after surgical intervention. Treatment recommendations may need to be updated to reflect new data as they becomes available.

\section{Surgical Decision Making in Patients With Moderate IMR Undergoing CABG}

The 2014 AHA/American College of Cardiology Foundation guidelines include recommendations for surgery for 
moderate IMR are relatively conservative. MV repair with CABG is significantly more effective than CABG alone in reducing or eliminating moderate IMR, although this superior effectiveness did not translate into differences in LV reverse remodeling, survival, or rates of MACCE. ${ }^{2,53}$ The addition of MV repair was associated with a greater number of early serious neurologic events and supraventricular arrhythmias. Two previous randomized trials with smaller patient sample sizes found a significant benefit of combined CABG/MV repair for patients with CAD and moderate IMR, including better reduction of MR and improvements in LVEF, LV endsystolic diameter, and NYHA functional class. ${ }^{76,77}$ In these studies, there were no differences between groups in early mortality or longer-term survival. The methodologic limitations and small sample sizes of the trials should be acknowledged.

Although guidelines support the heart team in choosing to perform $\mathrm{CABG}$ alone or $\mathrm{CABG}$ plus $\mathrm{MV}$ repair for patients with moderate IMR who have a clinical indication for surgical coronary revascularization, they do not provide strong guidance as to which patients will benefit most from either procedure. This decision can be challenging and typically falls to the responsible surgeon. In choosing CABG alone or CABG plus MV repair, surgeons can consider several variables that might influence decision making, although validation is lacking.

1. What symptom(s) are predominant? Angina, shortness of breath/dyspnea on exertion/HF, or both? Might the presence of diabetes complicate interpretation of these symptoms? Patients, families, and referring physicians generally want these presenting symptoms to be addressed; when dyspnea is an important symptom in the setting of documented moderate IMR, the surgeon logically may feel that MV repair should be added to planned CABG, especially if left-sided filling pressures are elevated at the time of catheterization and no other cause is apparent. Conversely, if angina without dyspnea is the presentation, CABG alone may be all that is warranted. Although not supported by a robust evidence base, this approach remains compelling to many surgeons and cardiologists.

2. What incremental risk would the addition of MV repair to $\mathrm{CABG}$ alone impose on this particular patient? This question must include consideration of surgeon/centerspecific outcomes with mitral and coronary surgery and patient-specific comorbidities that might significantly increase risk of adverse events with prolonged cardiopulmonary bypass/crossclamp time. In centers in which MV repair is practiced expertly, the incremental risk may be low. Conversely, for a surgical team inexperienced in MV repair, CABG alone may be a more reliable alternative. Indeed, the complexity of the planned
CABG itself may reasonably influence the decision to add MV repair to the procedure. If numerous difficult or precarious coronary arteries must be bypassed, the operating team may reasonably seek to limit the duration and cumulative difficulty of the procedure by not adding a MV repair. Similarly, the frailty of the patient also may be an important consideration. Very elderly, frail patients, and those with severe comorbidities (chronic obstructive pulmonary disease, peripheral vascular disease, previous stroke, renal failure, etc) may benefit from a "less is more" approach to CAD in the setting of moderate IMR, unless HF is problematic. For some patients, the addition of MV repair to CABG may be inappropriate if ascending aortic calcification or other risk factors mandate an off-pump approach.

3. Although the aforementioned general considerations are reasonable, thoughtful heart team members may seek to more specifically identify preoperatively which patients will have reduction of moderate IMR with CABG alone and which patients will require MV repair. It is intuitive to believe that $\mathrm{CABG}$ alone will improve this pathophysiological situation only if the posterolateral $\mathrm{LV}$ is viable, ischemic, and bypassable. If the posterolateral LV supporting the posterior papillary muscle is infarcted grossly, thinned, or aneurysmal, revascularization is unlikely to improve regional wall motion or secondary MR. Similarly, if no suitable coronary artery target exists in this region, significant improvement in regional wall motion and subsequently in secondary MR is unlikely with $\mathrm{CABG}$ alone.

4. Annular dilatation (Type I dysfunction) that exceeds 38 to $40 \mathrm{~mm}$ in diameter also may play a role in IMR when significant ventricular enlargement is present and may reasonably influence surgical decision making toward adding MV repair to planned CABG. Significant enlargement of the LA suggests that chronic MR is important and similarly may guide the surgeon toward adding MV repair to $\mathrm{CABG}$ alone.

a. In patients with moderate IMR undergoing CABG, MV repair with an undersized complete rigid annuloplasty ring may be considered (COR IIb, LOE B). ${ }^{2,53}$

\section{Technical Aspects of MV Repair for IMR}

For IMR operations, meticulous attention should be paid to myocardial preservation and cardiopulmonary perfusion. At the time of exposure of the MV, it can be noted that the MV appears "normal." The surgical reduction in anteroposterior diameter and orifice area of the MV is an overcorrection and overcompensation for a disease of the ventricle. This undersizing of the mitral ring was first proposed by Bolling in 1995 and has become a standard 
technical approach for IMR repair. ${ }^{78}$ When undersizing a mitral ring, it is recommended that one use a very large number of annular sutures, as compared with degenerative MR repairs, to distribute the workload of annular reductive force. These sutures may be put in very closely together, or even on a diagonal. Some advocate the use of pledgetted sutures or the use of an extra row or a few pledgetted reinforcement sutures posteriorly, once the ring is tied in place.

The vast majority of patients may be well served with a "small" 26 or 28 ring. Although initially in series of IMR patients there was concern for both systolic anterior motion of the anterior leaflet and/or mitral stenosis from such downsizing, these have not resulted in adverse clinical sequelae in any long-term follow-up series. The type of ring used for IMR repairs is an important technical consideration. In a landmark paper by Hueb and colleagues, ${ }^{13}$ it was noted that the fibrous portion of the mitral annulus anteriorly between the 2 mitral trigones dilated proportionally and as much as the posterior muscular annulus. This directs the technical approach to IMR valve repair and hints at why some previous approaches to IMR valve repair that used incomplete and/or flexible bands had a very high rate of failure. Magne and colleagues ${ }^{79}$ reported failure rates of up to $80 \%$ at 6 months postoperatively, with recurrence of at least $2+$ MR with large flexible and/or partial bands for patients with IMR. Many other reports have shown that partial bands result in unacceptable rates of recurrent MR (McGee and colleagues $^{81}$ ), and it has been shown that this residual IMR leads to little effective reverse LV remodeling and poor outcomes. ${ }^{68,80-82}$

In a comparison trial of patients treated with MV repair for IMR, Spoor and colleagues ${ }^{83}$ reported a 5 -fold greater incidence of recurrent IMR with the use of flexible rings as opposed to small complete rigid rings. ${ }^{83}$ Finally, Silberman and colleagues ${ }^{84}$ reported on predictors of residual and recurrent IMR and the 2 strongest multivariate predictors were LV size and the type of ring. In fact, the type of ring was a better predictor than LV size. That study showed that small rigid and complete rings were best for IMR. In this specific disease state of IMR, large partial or incomplete rings probably do not result in a durable repair for IMR and are not favored technically. Presently, there are numerous specific small rigid and complete IMR rings with a disproportionate AP diameter dimension reduction. Although none of these rings have shown clinical outcome differences between them, they are probably most favored for the technical repair of functional mitral regurgitation (FMR).

When the patient is coming off cardiopulmonary bypass, there should be no MR seen on intraoperative TEE. Moreover, the zone of coaptation should be measured and should be at least 8 - to 10 -mm long (deep). If this is not the case under anesthesia, then the patient certainly has a much greater risk of recurrent MR when awakened and removed from the vascular unloading effects of general anesthesia.

There are other adjunct therapies that have been used for repair of IMR. There are often deep clefts between P1 and $\mathrm{P} 2$, and between $\mathrm{P} 2$ and $\mathrm{P} 3$, which should be closed. Others (Borger and colleagues ${ }^{9}$ ) have advocated dividing secondary chords to both the anterior and posterior leaflets to allow for a longer zone of coaptation. Although this method has been successful technically, there is no long-term followup and there has been concern expressed in the literature about the effect on ventricular function of disrupting any chordal structures in these already-compromised ventricles.

\section{Replacement in IMR}

There is a clear consensus on the technical aspects of MV replacement for IMR. MV replacement should be a total valve-sparing replacement. A randomized trial comparing partial versus complete chordal-sparing MV replacement demonstrated that $\mathrm{LV}$ volume and function were much better preserved with complete sparing versus posterior leaflet-sparing techniques. ${ }^{85}$ For IMR, nonvalve-sparing mitral replacement should be abandoned completely. There are numerous techniques for total valve-sparing MV replacement in IMR, including anterior flip-over, in which a C-shaped incision curved is placed in the anterior leaflet and the entire anterior apparatus is moved posteriorly. After appropriate valve sizing, pledgetted sutures are placed through the posterior annulus, the edge of the posterior leaflet, and the anterior leaflet, placing both chordal apparatus and leaflets behind the MV prosthesis. A second method of achieving this is to remove the center of the anterior leaflet and to then rotate the remaining portions of the anterior leaflet to the left and right commissures. Valve sizing for IMR should be prudent and not "oversized." With modern MV prostheses, there should not be a worry of stenosis, and overly large bulky valves may impair LV dynamics and intraventricular conduction in these already-poor LVs.

- MVR for IMR is performed with complete preservation of both anterior and posterior leaflet chords (COR I, LOE B). ${ }^{1,52}$

- MV repair for IMR is performed with small undersized complete rigid annuloplasty ring (COR IIa, LOE B). ${ }^{1,52}$

\section{SECTION VI: PERCUTANEOUS TRANSCATHETER MITRAL REPAIR GUIDELINES FOR TREATMENT OF IMR}

IMR is a marker for significant morbidity and mortality. Although some patients are treated with mitral surgery, many of these patients are not referred for mitral surgery often as the result of comorbid diseases. The MitraClip System (Abbott Vascular; Santa Clara, Calif) is a percutaneous transcatheter mitral repair based on the 
technique of Alfieri. Based on the EVEREST II trial, ${ }^{86}$ and its use in high-risk patients, ${ }^{87}$ it is currently approved by the Food and Drug Administration in the United States for symptomatic patients with primary (degenerative) MR who are at prohibitive risk for surgery as determined by the heart team. For FMR, the MitraClip device has received a class IIb recommendation by the European Society of Cardiology, similar to the recommendations for open mitral surgery. In the United States, the device is under investigation for FMR through the Clinical Outcomes Assessment of the MitraClip Percutaneous Therapy for Extremely HighSurgical-Risk Patients (COAPT) trial (ClinicalTrials.gov \#NCT01626079).

\section{The MitraClip Procedure}

The MitraClip procedure has been well detailed previously. ${ }^{88}$ The procedure typically is performed in a cardiac catheterization suite or hybrid operating room. With the patient under general anesthesia, TEE is performed. An arterial line is not necessary but can be helpful. Pulmonary artery pressures are measured before and after, although continuous monitoring is not necessary. Femoral venous access is obtained typically in the right groin. A transseptal puncture is performed, although, unlike standard techniques, the particular location of this puncture is critical to allow optimal navigation in the LA for accurate placement of the device. The patient is systemically heparinized and the puncture site in the interatrial septum is dilated, followed by advancement of the 24-F guide sheath from the femoral vein to the right atrium, and then across the atrial septum. The MitraClip device is guided into optimal position and orientation with the use of 2-dimensional and 3D TEE. The clip arms are opened to orient them perpendicular to the line of MV coaptation and then advanced into the LV. The device is then retracted underneath the mitral leaflets, and the frictional gripper arms are dropped onto the atrial side of the leaflets, and the device itself closed to pull more of the leaflet tissue into the device. Adequate insertion of the leaflets in the device and reduction in MR are then assessed by TEE. If not sufficient, the device can be opened, leaflets released, and another attempt can be performed as many times as necessary. Once leaflet insertion and MR reduction are adequate, the device can then be released. Additional devices can be placed in a similar manner to optimize MR reduction while avoiding creation of mitral stenosis. On the completion of the procedure, the steerable guide is removed and heparin is reversed. A purse string subcutaneous suture may be placed at the femoral venous access site to achieve hemostasis.

\section{MitraClip Data in FMR}

Data are available on the MitraClip procedure in patients with FMR, particularly outside the United States. ${ }^{89}$ The
MitraClip received the CE Mark in 2008. Since 2009, the ACCESS-EU registry has been enrolling patients. Of 567 patients treated, $77 \%$ had FMR. These patients had a logistic EuroSCORE of $24.8 \%$, with the majority in NYHA class 3-4 congestive heart failure. ${ }^{90}$ The operative and 1-year mortality were $2.8 \%$ and $17 \%$, respectively. Reduction of MR to $<2+$ was achieved in $91.6 \%$ at discharge, whereas $78.5 \%$ remained with $<2+$ MR at 1 -year follow-up. This resulted in an improvement in the 6-minute walk test from $274.7 \mathrm{ft}$ to $334.2 \mathrm{ft}$ at 2 years' follow-up. ${ }^{90}$

A second registry in Europe called the SENTINEL registry includes 25 centers in 8 European countries. From 2011 to 2012 , a total of 628 patients were treated with the MitraClip, including $72 \%$ with FMR. ${ }^{91}$ The procedural mortality was $2.9 \%$ with an estimated 1 -year mortality of $15.3 \%$. The rehospitalization rate was $25.8 \%$ in patients undergoing FMR after MitraClip. ${ }^{91}$

At Alfieri's own center, 109 consecutive high-risk surgical cases were treated with MitraClip. They reported treating a challenging cohort of patients with a mean EF of $28 \%$, chronic renal failure in $47 \%$, and a mean EuroSCORE of $22 \% .^{92}$ The 30 -day mortality was a remarkable $1.8 \%$. At 12 months, $87 \%$ had MR less than or equal to $2+$, and the mean EF improved to $34.7 \%(P=.002){ }^{92}$

In the United States, published data in FMR are limited. The EVEREST II (Endovascular Valve Edge-to-Edge Repair) High Risk Study was completed recently. Of 78 patients treated, 46 patients had FMR. ${ }^{93}$ MitraClip procedure success was obtained in $96 \%$. The 30 -day mortality was $7.7 \%$, which compared favorably with the predicted Society of Thoracic Surgeons operative mortality of $14.2 \%$. The 12-month survival was $76 \%$. These patients were compared with a group of similar patients screened for MitraClip but who were not enrolled and were treated with medical therapy. The 12-month survival in the medically treated group was only $55 \%$. These data suggest that MitraClip may have a beneficial effect on survival. Moreover, $79 \%$ of the patients who received FMR had $\leq 2+$ MR at 1 year, and $80 \%$ had at an improvement in NYHA functional class of at least 1 or more. ${ }^{93}$ These data formed the foundation for the COAPT trial.

\section{COAPT Trial}

The COAPT trial currently is underway at more than 80 sites in the United States to investigate the safety and effectiveness of the MitraClip in comparison with standard medical therapy for HF in symptomatic patients with $\geq 3+$ FMR who have been determined by the local heart team as not appropriate for MV surgery. Patients will need to be on stable and optimized, goal-directed medical therapy before enrollment. Once enrolled, patients are randomized to the MitraClip procedure or medical therapy for $\mathrm{HF}$ alone. The primary safety endpoint consists of a composite of device embolization, single leaflet detachment, development of 
mitral stenosis, need for left ventricular assist device, transplant, or any other nonelective cardiovascular surgery related to the device or procedure at 12 months. The primary effectiveness endpoint is rehospitalizations for HF at 24 months. Although the trial is not powered for mortality, this endpoint will be captured as a secondary endpoint. This trial will be one of the largest and most informative studies in FMR and is expected to shape future surgical and transcatheter trials for this disease.

\section{Heart Team Assessment}

A particular focus for valve therapy recently has been patient assessment by the heart team. This was created initially during clinical trials but has persisted due to Food and Drug Administration labeling and the belief that outcomes are superior due to better patient selection. The heart team at many centers has expanded to include not just the cardiac surgeon and interventional cardiologist but also the HF cardiologist, imaging cardiologist, and geriatrician. In addition, because of comorbidities, most centers have identified a pulmonologist, nephrologist, hepatologist, and oncologist to aid in the assessment of select patients. The members of the heart team assess the patient either independently or jointly, review relevant studies, and make a uniform decision about the optimal therapy for the patient.

\section{SECTION VII: CONCLUSIONS}

IMR is a disease of the ventricle. There are specific imaging criteria to define severity of MR, best performed with an integrative approach. Surgical therapy is appropriate for selected symptomatic patients. Mitral repair versus replacement has had equivalent mortality for severe IMR but is associated with significantly more residual/recurrent regurgitation, which in turn may relate in more HF events and cardiovascular readmissions. Moderate IMR might be successfully treated with CABG alone if the primary symptom is angina and a graftable vessel is present in ischemic, viable territory in the distribution of the supporting posterolateral papillary muscle. The role of percutaneous transcatheter mitral repair (MitraClip) has been defined for degenerative MV disease but not yet for IMR. This technology may play a role in high-risk patients. Longer-term follow-up of patients enrolled in existing clinical trials will better define appropriate interventional modalities.

\section{Conflict of Interest Statement}

Dr Adams has received institutional royalties for patents and institutional grants from Edwards Lifesciences; institutional royalties for patents and institutional grants from Medtronic; and institutional grants from NeoChord. Dr Ailawadi reports personal fees from Abbott Vascular, Edwards Lifesciences, St. Jude Medical, Mitralign, and Atricure. Dr Mack reports a potential conflict of interest exists as the Co-
PI of COAPT Trial; Abbott Vascular is trial sponsor- uncompensated. All other authors have nothing to disclose with regard to commercial support.

\section{References}

1. Goldstein D, Moskowitz AJ, Gelijns AC, Ailawadi G, Parides MK, Perrault LP, et al. Two-year outcomes of surgical treatment of severe ischemic mitral regurgitation. N Engl J Med. 2016;374:344-53.

2. Michler RE, Smith PK, Parides MK, Ailawadi G, Thourani V, Moskowitz AJ, et al. Two-year outcomes of surgical treatment of moderate ischemic mitral regurgitation. N Engl J Med. 2016:374:1932-41.

3. American Association for Thoracic Surgery Ischemic Mitral Regurgitation Consensus Guidelines Writing Committee, Kron IL, Acker MA, Adams DH, Ailawadi G, Bolling SF, Hung JW, et al. 2015 The American Association for Thoracic Surgery Consensus Guidelines: ischemic mitral valve regurgitation. $J$ Thorac Cardiovasc Surg. 2016;151:940-56.

4. Nishimura RA, Otto CM, Bonow RO, Carabello BA, Erwin JP III, Guyton RA, et al. 2014 AHA/ACC Guideline for the Management of Patients With Valvular Heart Disease: Executive Summary: A Report of the American College of Cardiology/American Heart Association Task Force on Practice Guidelines. J Am Coll Cardiol. 2014;129:2440-92.

5. Vahanian A, Alfieri O, Andreotti F, Antunes MJ, Barón-Esquivias G, Baumgartner H, et al. Guidelines on the management of valvular heart disease (version 2012). Eur Heart J. 2012;33:2451-96.

6. Carpentier A. Cardiac valve surgery - the "French correction." J Thorac Cardiovasc Surg. 1983;86:323-37.

7. Dagum P, Timek TA, Green GR, Lai D, Daughters GT, Liang DH, et al. Coordinate-free analysis of mitral valve dynamics in normal and ischemic hearts. Circulation. 2000;102:III62-9.

8. Timek TA, Lai DT, Tibayan F, Liang D, Daughters GT, Dagum P, et al. Ischemia in three left ventricular regions: insights into the pathogenesis of acute ischemic mitral regurgitation. J Thorac Cardiovasc Surg. 2003;125:559-69.

9. Borger MA, Murphy PM, Alam A, Fazel S, Maganti M, Armstrong S, et al. Initial results of the chordal-cutting operation for ischemic mitral regurgitation. $J$ Thorac Cardiovasc Surg. 2007;133:1483-92.

10. Kwan J, Shiota T, Agler DA, Popović ZB, Qin JX, Gillinov MA, et al. Geometric differences of the mitral apparatus between ischemic and dilated cardiomyopathy with significant mitral regurgitation: real-time three-dimensional echocardiography study. Circulation. 2003;107:1135-40.

11. Watanabe N, Ogasawara Y, Yamaura Y, Yamamoto K, Wada N, Kawamoto T, et al. Geometric differences of the mitral valve tenting between anterior and inferior myocardial infarction with significant ischemic mitral regurgitation: quantitation by novel software system with transthoracic real-time three-dimensional echocardiography. J Am Soc Echocardiogr. 2006;19:71-5.

12. Isnard R, Acar $\mathrm{C}$. The mitral annulus area: a useful tool for the surgeon. J Heart Valve Dis. 2008;17:243-50.

13. Hueb AC, Jatene FB, Moreira LF, Pomerantzeff PM, Kallás E, de Oliveira SA Ventricular remodeling and mitral valve modifications in dilated cardiomyopathy: new insights from anatomic study. J Thorac Cardiovasc Surg. 2002;124 1216-24.

14. Kaji S, Nasu M, Yamamuro A, Tanabe K, Nagai K, Tani T, et al. Annular geometry in patients with chronic ischemic mitral regurgitation: three-dimensional magnetic resonance imaging study. Circulation. 2005;112:I409-14.

15. Daimon M, Saracino G, Gillinov AM, Koyama Y, Fukuda S, Kwan J, et al. Local dysfunction and asymmetrical deformation of mitral annular geometry in ischemic mitral regurgitation: a novel computerized 3D echocardiographic analysis. Echocardiography. 2008;25:414-23.

16. Calafiore AM, Iacò AL, Gallina S, Al-Amri H, Penco M, Di Mauro M. Surgical treatment of functional mitral regurgitation. Int J Cardiol. 2013;166:559-71.

17. Godley RW, Wann LS, Rogers EW, Feigenbaum H, Weyman AE. Incomplete mitral leaflet closure in patients with papillary muscle dysfunction. Circulation. 1981;63:565-71.

18. Levine RA, Schwammenthal E. Ischemic mitral regurgitation on the threshold of a solution: from paradoxes to unifying concepts. Circulation. 2005; 112:745-58.

19. Calafiore AM, Gallina S, Di Mauro M, Gaeta F, Iacò AL, D’Alessandro S, et al. Mitral valve procedure in dilated cardiomyopathy: repair or replacement? Ann Thorac Surg. 2001;71:1146-52; discussion 1152-3.

20. Watanabe N, Ogasawara Y, Yamaura Y, Kawamoto T, Toyota E, Akasaka T, et al. Quantitation of mitral valve tenting in ischemic mitral regurgitation by 
transthoracic real-time three-dimensional echocardiography. J Am Coll Cardiol. 2005; $45: 763-9$

21. Kron IL, Hung J, Overbey JR, Bouchard D, Gelijns AC, Moskowitz AJ, et al. Predicting recurrent mitral regurgitation after mitral valve repair for severe ischemic mitral regurgitation. J Thorac Cardiovasc Surg. 2015;149:752-761.e751.

22. Helmcke F, Nanda NC, Hsiung MC, Soto B, Adey CK, Goyal RG, et al. Color Doppler assessment of mitral regurgitation with orthogonal planes. Circulation. 1987;75:175-83.

23. Spain MG, Smith MD, Grayburn PA, Harlamert EA, DeMaria AN. Quantitative assessment of mitral regurgitation by Doppler color flow imaging: angiographic and hemodynamic correlations. J Am Coll Cardiol. 1989;13: 585-90.

24. Zoghbi WA, Enriquez-Sarano M, Foster E, Grayburn PA, Kraft CD, Levine RA, et al. Recommendations for evaluation of the severity of native valvular regurgitation with two-dimensional and Doppler echocardiography. J Am Soc Echocardiogr. 2003; 16:777-802.

25. Hall SA, Brickner ME, Willett DL, Irani WN, Afridi I, Grayburn PA. Assessment of mitral regurgitation severity by Doppler color flow mapping of the vena contracta. Circulation. 1997:95:636-42.

26. Bargiggia GS, Tronconi L, Sahn DJ, Recusani F, Raisaro A, De Servi S, et al. A new method for quantitation of mitral regurgitation based on color flow Doppler imaging of flow convergence proximal to regurgitant orifice. Circulation. 1991; $84: 1481-9$.

27. Recusani F, Bargiggia GS, Yoganathan AP, Raisaro A, Valdes-Cruz LM, Sung HW, et al. A new method for quantification of regurgitant flow rate using color Doppler flow imaging of the flow convergence region proximal to a discrete orifice. An in vitro study. Circulation. 1991;83:594-604.

28. Utsunomiya T, Ogawa T, Doshi R, Patel D, Quan M, Henry WL, et al. Doppler color flow "proximal isovelocity surface area" method for estimating volume flow rate: effects of orifice shape and machine factors. J Am Coll Cardiol. 1991; 17:1103-11.

29. Pu M, Vandervoort PM, Griffin BP, Leung DY, Stewart WJ, Cosgrove DM, et al. Quantification of mitral regurgitation by the proximal convergence method using transesophageal echocardiography. Clinical validation of a geometric correction for proximal flow constraint. Circulation. 1995;92:2169-77.

30. Kahlert P, Plicht B, Schenk IM, Janosi RA, Erbel R, Buck T. Direct assessment of size and shape of noncircular vena contracta area in functional versus organic mitral regurgitation using real-time three-dimensional echocardiography. $J$ Am Soc Echocardiogr. 2008;21:912-21.

31. Yosefy C, Levine RA, Solis J, Vaturi M, Handschumacher MD, Hung J. Proximal flow convergence region as assessed by real-time 3-dimensional echocardiography: challenging the hemispheric assumption. J Am Soc Echocardiogr. 2007;20: 389-96.

32. Grayburn PA, Carabello B, Hung J, Gillam LD, Liang D, Mack MJ, et al. Defining "severe" secondary mitral regurgitation: emphasizing an integrated approach. J Am Coll Cardiol. 2014;64:2792-801.

33. Marwick TH, Zoghbi WA, Narula J. Redrawing the borders: considering guideline revision in functional mitral regurgitation. JACC Cardiovasc Imaging. 2014; 7:333-5.

34. Little SH, Pirat B, Kumar R, Igo SR, McCulloch M, Hartley CJ, et al. Threedimensional color Doppler echocardiography for direct measurement of vena contracta area in mitral regurgitation: in vitro validation and clinical experience. JACC Cardiovasc Imaging. 2008:1:695-704.

35. Thavendiranathan P, Phelan D, Thomas JD, Flamm SD, Marwick TH. Quantitative assessment of mitral regurgitation: validation of new methods. $J$ Am Coll Cardiol. 2012;60:1470-83.

36. Zeng X, Levine RA, Hua L, Morris EL, Kang Y, Flaherty M, et al. Diagnostic value of vena contracta area in the quantification of mitral regurgitation severity by color Doppler 3D echocardiography. Circ Cardiovasc Imaging. 2011;4: 506-13.

37. Nishimura RA, Otto CM, Bonow RO, Carabello BA, Erwin JP, Guyton RA, et al. 2014 AHA/ACC guideline for the management of patients with valvular heart disease: a report of the American College of Cardiology/American Heart Association Task Force on Practice Guidelines. J Thorac Cardiovasc Surg. 2014;148: e1-132.

38. Vahanian A, Alfieri O, Andreotti F, Antunes MJ, Barón-Esquivias G, Baumgartner $\mathrm{H}$, et al. Guidelines on the management of valvular heart disease (version 2012): the Joint Task Force on the Management of Valvular Heart Disease of the European Society of Cardiology (ESC) and the European Association for Cardio-Thoracic Surgery (EACTS). Eur J Cardiothorac Surg. 2012;42: S1-44.
39. Aklog L, Filsoufi F, Flores KQ, Chen RH, Cohn LH, Nathan NS, et al. Does coronary artery bypass grafting alone correct moderate ischemic mitral regurgitation? Circulation. 2001;104:I68-75.

40. Sheikh KH, Bengtson JR, Rankin JS, de Bruijn NP, Kisslo J. Intraoperative transesophageal Doppler color flow imaging used to guide patient selection and operative treatment of ischemic mitral regurgitation. Circulation. 1991;84:594-604.

41. Grigioni F, Enriquez-Sarano M, Zehr KJ, Bailey KR, Tajik AJ. Ischemic mitral regurgitation: long-term outcome and prognostic implications with quantitative Doppler assessment. Circulation. 2001;103:1759-64.

42. Trichon BH, Felker GM, Shaw LK, Cabell CH, O'Connor CM. Relation of frequency and severity of mitral regurgitation to survival among patients with left ventricular systolic dysfunction and heart failure. Am J Cardiol. 2003;91:538-43.

43. Yancy CW, Jessup M, Bozkurt B, Butler J, Casey DE, Drazner MH, et al. 2013 ACCF/AHA guideline for the management of heart failure: a report of the American College of Cardiology Foundation/American Heart Association Task Force on Practice Guidelines. J Am Coll Cardiol. 2013;62:e147-239.

44. Agricola E, Ielasi A, Oppizzi M, Faggiano P, Ferri L, Calabrese A, et al. Longterm prognosis of medically treated patients with functional mitral regurgitation and left ventricular dysfunction. Eur J Heart Fail. 2009;11:581-7.

45. Capomolla S, Febo O, Gnemmi M, Riccardi G, Opasich C, Caporotondi A, et al. Beta-blockade therapy in chronic heart failure: diastolic function and mitral regurgitation improvement by carvedilol. Am Heart J. 2000;139:596-608.

46. Comin-Colet J, Sánchez-Corral MA, Manito N, Gómez-Hospital JA, Roca J, Fernández-Nofrerias E, et al. Effect of carvedilol therapy on functional mitral regurgitation, ventricular remodeling, and contractility in patients with heart failure due to left ventricular systolic dysfunction. Transplant Proc. 2002;34:177-8.

47. Cleland JG, Daubert JC, Erdmann E, Freemantle N, Gras D, Kappenberger L, et al. The effect of cardiac resynchronization on morbidity and mortality in heart failure. N Engl J Med. 2005;352:1539-49.

48. van Bommel RJ, Marsan NA, Delgado V, Borleffs CJ, van Rijnsoever EP, Schalij MJ, et al. Cardiac resynchronization therapy as a therapeutic option in patients with moderate-severe functional mitral regurgitation and high operative risk. Circulation. 2011;124:912-9.

49. Wu AH, Aaronson KD, Bolling SF, Pagani FD, Welch K, Koelling TM. Impact of mitral valve annuloplasty on mortality risk in patients with mitral regurgitation and left ventricular systolic dysfunction. J Am Coll Cardiol. 2005;45 381-7.

50. Milano CA, Daneshmand MA, Rankin JS, Honeycutt E, Williams ML, Swaminathan M, et al. Survival prognosis and surgical management of ischemic mitral regurgitation. Ann Thorac Surg. 2008;86:735-44.

51. Silberman S, Oren A, Klutstein MW, Deeb M, Asher E, Merin O, et al. Does mitral valve intervention have an impact on late survival in ischemic cardiomyopathy? Isr Med Assoc J. 2006;8:17-20.

52. Acker MA, Parides MK, Perrault LP, Moskowitz AJ, Gelijns AC, Voisine P, et al Mitral-valve repair versus replacement for severe ischemic mitral regurgitation. N Engl J Med. 2014;370:23-32.

53. Smith PK, Puskas JD, Ascheim DD, Voisine P, Gelijns AC, Moskowitz AJ, et al. Surgical treatment of moderate ischemic mitral regurgitation. $N$ Engl J Med. 2014;371:2178-88.

54. Vassileva CM, Boley T, Markwell S, Hazelrigg S. Meta-analysis of short-term and long-term survival following repair versus replacement for ischemic mitra regurgitation. Eur J Cardiothorac Surg. 2011;39:295-303.

55. Di Salvo TG, Acker MA, Dec GW, Byrne JG. Mitral valve surgery in advanced heart failure. J Am Coll Cardiol. 2010;55:271-82.

56. Gillinov AM, Wierup PN, Blackstone EH, Bishay ES, Cosgrove DM, White J, et al. Is repair preferable to replacement for ischemic mitral regurgitation? J Thorac Cardiovasc Surg. 2001;122:1125-41.

57. Grossi EA, Goldberg JD, LaPietra A, Ye X, Zakow P, Sussman M, et al. Ischemic mitral valve reconstruction and replacement: comparison of long-term survival and complications. J Thorac Cardiovasc Surg. 2001;122:1107-24.

58. Lorusso R, Gelsomino S, Vizzardi E, D'Aloia A, De Cicco G, Lucà F, et al. Mitra valve repair or replacement for ischemic mitral regurgitation? The Italian Study on the Treatment of Ischemic Mitral Regurgitation (ISTIMIR). J Thorac Cardiovasc Surg. 2013;145:128-39; discussion 137-8.

59. Kron IL, Hung J, Overbey JR, Bouchard D, Gelijns AC, Moskowitz AJ, et al. Predicting recurrent mitral regurgitation after mitral valve repair for severe ischemic mitral regurgitation. J Thorac Cardiovasc Surg. 2015;149:752-761.e751.

60. Bax JJ, Braun J, Somer ST, Klautz R, Holman ER, Versteegh MI, et al. Restrictive annuloplasty and coronary revascularization in ischemic mitral regurgitation results in reverse left ventricular remodeling. Circulation. 2004;110:II103-8. 
61. Gelsomino S, Lorusso R, De Cicco G, Capecchi I, Rostagno C, Caciolli S, et al. Five-year echocardiographic results of combined undersized mitral ring annuloplasty and coronary artery bypass grafting for chronic ischaemic mitral regurgitation. Eur Heart J. 2008;29:231-40.

62. Haan CK, Cabral CI, Conetta DA, Coombs LP, Edwards FH. Selecting patients with mitral regurgitation and left ventricular dysfunction for isolated mitral valve surgery. Ann Thorac Surg. 2004;78:820-5.

63. Lee AP, Acker M, Kubo SH, Bolling SF, Park SW, Bruce CJ, et al. Mechanisms of recurrent functional mitral regurgitation after mitral valve repair in nonischemic dilated cardiomyopathy: importance of distal anterior leaflet tethering. Circulation. 2009;119:2606-14.

64. Magne J, Sénéchal M, Dumesnil JG, Pibarot P. Ischemic mitral regurgitation: a complex multifaceted disease. Cardiology. 2009;112:244-59.

65. Onorati F, Rubino AS, Marturano D, Pasceri E, Santarpino G, Zinzi S, et al Midterm clinical and echocardiographic results and predictors of mitral regurgitation recurrence following restrictive annuloplasty for ischemic cardiomyopathy. J Thorac Cardiovasc Surg. 2009;138:654-62.

66. Ciarka A, Braun J, Delgado V, Versteegh M, Boersma E, Klautz R, et al. Predictors of mitral regurgitation recurrence in patients with heart failure undergoing mitral valve annuloplasty. Am J Cardiol. 2010;106:395-401.

67. Crabtree TD, Bailey MS, Moon MR, Munfakh N, Pasque MK, Lawton JS, et al Recurrent mitral regurgitation and risk factors for early and late mortality after mitral valve repair for functional ischemic mitral regurgitation. Ann Thorac Surg. 2008;85:1537-42; discussion 1542-3.

68. De Bonis M, Lapenna E, Verzini A, La Canna G, Grimaldi A, Torracca L, et al. Recurrence of mitral regurgitation parallels the absence of left ventricular reverse remodeling after mitral repair in advanced dilated cardiomyopathy. Ann Thorac Surg. 2008:85:932-9.

69. Digiammarco G, Liberi R, Giancane M, Canosa C, Gallina S, Di Francesco A, et al. Recurrence of functional mitral regurgitation in patients with dilated cardiomyopathy undergoing mitral valve repair: how to predict it. Interact Cardiovasc Thorac Surg. 2007:6:340-4.

70. Gelsomino S, van Garsse L, Lucà F, Lorusso R, Cheriex E, Rao CM, et al. Impact of preoperative anterior leaflet tethering on the recurrence of ischemic mitral regurgitation and the lack of left ventricular reverse remodeling after restrictive annuloplasty. J Am Soc Echocardiogr. 2011;24:1365-75.

71. Lee LS, Kwon MH, Cevasco M, Schmitto JD, Mokashi SA, McGurk S, et al. Postoperative recurrence of mitral regurgitation after annuloplasty for functional mitral regurgitation. Ann Thorac Surg. 2012;94:1211-6; discussion 1216-7.

72. Shiota M, Gillinov AM, Takasaki K, Fukuda S, Shiota T. Recurrent mitral regurgitation late after annuloplasty for ischemic mitral regurgitation. Echocardiography. 2011;28:161-6.

73. Ueno T, Sakata R, Iguro Y, Yamamoto H, Ueno M, Matsumoto K. Preoperative advanced left ventricular remodeling predisposes to recurrence of ischemic mitral regurgitation with less reverse remodeling. J Heart Valve Dis. 2008;17:36-41.

74. Bouma W, van der Horst IC, Wijdh-den Hamer IJ, Erasmus ME, Zijlstra F, Mariani MA, et al. Chronic ischaemic mitral regurgitation. Current treatment results and new mechanism-based surgical approaches. Eur J Cardiothorac Surg. 2010;37:170-85.

75. Szymanski C, Bel A, Cohen I, Touchot B, Handschumacher MD, Desnos M, et al Comprehensive annular and subvalvular repair of chronic ischemic mitral regurgitation improves long-term results with the least ventricular remodeling. $\mathrm{Circu}$ lation. 2012;126:2720-7.

76. Chan KM, Punjabi PP, Flather M, Wage R, Symmonds K, Roussin I, et al. Coronary artery bypass surgery with or without mitral valve annuloplasty in moderate functional ischemic mitral regurgitation: final results of the Randomized Ischemic Mitral Evaluation (RIME) trial. Circulation. 2012;126:2502-10.
77. Fattouch K, Sampognaro R, Speziale G, Salardino M, Novo G, Caruso M, et al Impact of moderate ischemic mitral regurgitation after isolated coronary artery bypass grafting. Ann Thorac Surg. 2010;90:1187-94.

78. Bach DS, Bolling SF. Improvement following correction of secondary mitra regurgitation in end-stage cardiomyopathy with mitral annuloplasty. Am J Car diol. 1996:78:966-9.

79. Magne J, Sénéchal M, Mathieu P, Dumesnil JG, Dagenais F, Pibarot P. Restrictive annuloplasty for ischemic mitral regurgitation may induce functional mitral stenosis. J Am Coll Cardiol. 2008;51:1692-701.

80. Enriquez-Sarano M, Nkomo V, Mohty D, Avierinos JF, Chaliki H. Mitral regurgitation: predictors of outcome and natural history. Adv Cardiol. 2002;39:133-43.

81. McGee EC, Gillinov AM, Blackstone EH, Rajeswaran J, Cohen G, Najam F, et al. Recurrent mitral regurgitation after annuloplasty for functional ischemic mitral regurgitation. J Thorac Cardiovasc Surg. 2004;128:916-24.

82. Nagasaki M, Nishimura S, Ohtaki E, Kasegawa H, Matsumura T, Nagayama M, et al. The echocardiographic determinants of functional mitral regurgitation differ in ischemic and non-ischemic cardiomyopathy. Int J Cardiol. 2006;108: 171-6.

83. Spoor MT, Geltz A, Bolling SF. Flexible versus nonflexible mitral valve rings for congestive heart failure: differential durability of repair. Circulation. 2006;114: I67-71.

84. Silberman S, Klutstein MW, Sabag T, Oren A, Fink D, Merin O, et al. Repair of ischemic mitral regurgitation: comparison between flexible and rigid annuloplasty rings. Ann Thorac Surg. 2009;87:1721-6; discussion 1726-7.

85. Yun KL, Sintek CF, Miller DC, Pfeffer TA, Kochamba GS, Khonsari S, et al. Randomized trial comparing partial versus complete chordal-sparing mitral valve replacement: effects on left ventricular volume and function. $J$ Thorac Cardiovasc Surg. 2002;123:707-14

86. Feldman T, Foster E, Glower DD, Glower DG, Kar S, Rinaldi MJ, et al. Percutaneous repair or surgery for mitral regurgitation. N Engl J Med. 2011;364: $1395-406$.

87. Lim DS, Reynolds MR, Feldman T, Kar S, Herrmann HC, Wang A, et al Improved functional status and quality of life in prohibitive surgical risk patients with degenerative mitral regurgitation after transcatheter mitral valve repair. $J$ Am Coll Cardiol. 2014;64:182-92.

88. Pope NH, Ailawadi G. Transcatheter Mitral Valve Repair. Oper Tech Thorac Cardiovasc Surg. 2014;19:219-37.

89. D'Ascenzo F, Moretti C, Marra WG, Montefusco A, Omede P, Taha S, et al Meta-analysis of the usefulness of mitraclip in patients with functional mitral regurgitation. Am J Cardiol. 2015;116:325-31.

90. Maisano F, Franzen O, Baldus S, Schafer U, Hausleiter J, Butter C, et al. Percutaneous mitral valve interventions in the real world: early and 1-year results from the ACCESS-EU, a prospective, multicenter, nonrandomized postapproval study of the MitraClip therapy in Europe. J Am Coll Cardiol. 2013; 62:1052-61

91. Nickenig G, Estevez-Loureiro R, Franzen O, Tamburino C, Vanderheyden M, Lüscher TF, et al. Percutaneous mitral valve edge-to-edge repair: in-hospital re sults and 1-year follow-up of 628 patients of the 2011-2012 Pilot European Sentinel Registry. J Am Coll Cardiol. 2014;64:875-84.

92. Taramasso M, Maisano F, Latib A, Denti P, Buzzatti N, Cioni M, et al. Clinical outcomes of MitraClip for the treatment of functional mitral regurgitation. EuroIntervention. 2014;10:746-52.

93. Whitlow PL, Feldman T, Pedersen WR, Lim DS, Kipperman R, Smalling R, et al. Acute and 12-month results with catheter-based mitral valve leaflet repair: the EVEREST II (Endovascular Valve Edge-to-Edge Repair) High Risk Study. J Am Coll Cardiol. 2012;59:130-9. 